\title{
Designing of the $\mathrm{N}$-ethyl-4-(pyridin-4-yl)benzamide based potent ROCK1 inhibitors using docking, molecular dynamics, and 3D-QSAR
}

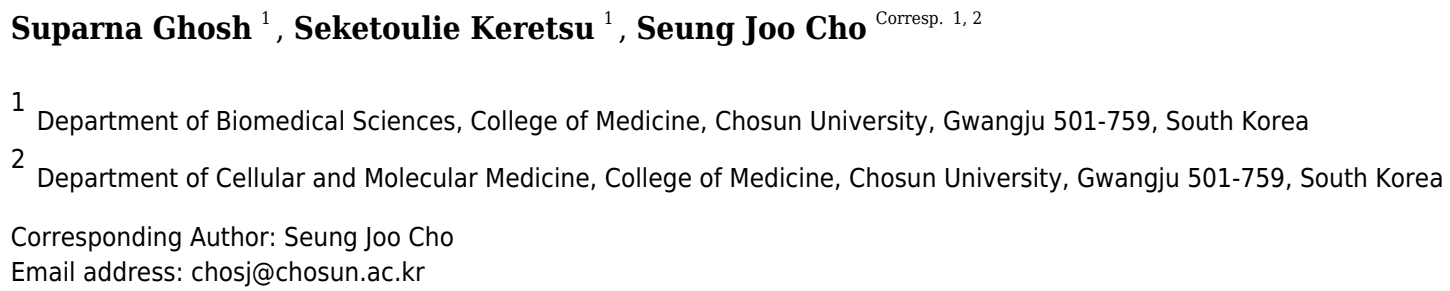

Rho-associated kinase-1 (ROCK1) has been recognized for its pivotal role in heart diseases, different types of malignancy, and many neurological disorders. Hyperactivity of ROCK phosphorylates the protein kinase-C (PKC), which ultimately induces smooth muscle cell contraction in the vascular system. Inhibition of ROCK1 has been shown to be a promising therapy for patients with cardiovascular disease. In this study, we have conducted molecular modeling techniques such as docking, molecular dynamics (MD), and 3Dimensional structure-activity relationship (3D-QSAR) on a series of N-ethyl-4-(pyridin-4yl)benzamide-based compounds. Docking and MD showed critical interactions and binding affinities between ROCK1 and its inhibitors. To establish the structure-activity relationship (SAR) of the compounds, 3D-QSAR techniques such as Comparative Molecular Field Analysis (CoMFA) and Comparative Molecular Similarity Indices Analysis (CoMSIA) were used. The CoMFA $\left(q^{2}=0.774, r^{2}=0.965, \mathrm{ONC}=6\right.$, and $\left.r_{\text {pred }}^{2}=0.703\right)$ and CoMSIA $\left(q^{2}=\right.$ $0.676, r^{2}=0.949, \mathrm{ONC}=6$, and $r_{\text {pred }}^{2}=0.548$ ) both models have shown reasonable external predictive activity, and contour maps revealed favorable and unfavorable substitutions for chemical group modifications. Based on the contour maps, we have designed forty new compounds, among which, seven compounds exhibited higher predictive activity $\left(\mathrm{pIC}_{50}\right)$. Further, we conducted the MD study, ADME/Tox, and SA score prediction using the seven newly designed compounds. The combination of docking, MD, and 3D-QSAR studies helps to understand the coherence modification of existing molecules. Our study may provide valuable insight into the development of more potent ROCK1 inhibitors. 
1 Designing of the $\mathbf{N}$-ethyl-4-(pyridin-4-yl)benzamide

2 based potent ROCK1 inhibitors using Docking,

3 Molecular Dynamics, and 3D-QSAR

5

Suparna Ghosh ${ }^{1}$, Seketoulie Keretsu ${ }^{1}$, Seung Joo Cho ${ }^{1,2, ~} \bowtie$

$7 \quad{ }^{1}$ Department of Biomedical Sciences, College of Medicine, Chosun University, Gwangju 501-

8 759, Republic of Korea; s.ghosh@chosun.kr (S.G); keretsu@chosun.kr (S.K);

9 chosj@chosun.ac.kr (S.J.C)

10 2Department of Cellular and Molecular Medicine, College of Medicine, Chosun University,

11 Gwangju 501-759, Republic of Korea

${ }^{凶}$ Corresponding Author:

Seung Joo Cho

Gwangju 501-759, Republic of Korea

32 Email address: chosj@chosun.ac.kr;

33 Tel.: +82-62-230-7482 (office) or +82-11-479-1010 (cell phone) 


\title{
Designing of the N-ethyl-4-(pyridin-4-yl)benzamide based potent ROCK1 inhibitors using Docking, Molecular Dynamics, and 3D-QSAR
}

\author{
Suparna Ghosh ${ }^{1}$, Seketoulie Keretsu ${ }^{1}$, Seung Joo Cho ${ }^{1,2, 凶}$
}

${ }^{1}$ Department of Biomedical Sciences, College of Medicine, Chosun University, Gwangju 501759, Republic of Korea; s.ghosh@chosun.kr (S.G); keretsu@chosun.kr (S.K); chosj@chosun.ac.kr (S.J.C) 2Department of Cellular and Molecular Medicine, College of Medicine, Chosun University, Gwangju 501-759, Republic of Korea

${ }^{凶}$ Corresponding Author:

Seung Joo Cho

Gwangju 501-759, Republic of Korea

Email address: chosj@chosun.ac.kr;

Tel.: +82-62-230-7482 (office) or +82-11-479-1010 (cell phone)

\section{Abstract}

Rho-associated kinase-1 (ROCK1) has been recognized for its pivotal role in heart diseases, different types of malignancy, and many neurological disorders. Hyperactivity of ROCK phosphorylates the protein kinase-C (PKC), which ultimately induces smooth muscle cell contraction in the vascular system. Inhibition of ROCK1 has been shown to be a promising therapy for patients with cardiovascular disease.

In this study, we have conducted molecular modeling techniques such as docking, molecular dynamics (MD), and 3-Dimensional structure-activity relationship (3D-QSAR) on a series of Nethyl-4-(pyridin-4-yl)benzamide-based compounds. Docking and MD showed critical interactions and binding affinities between ROCK1 and its inhibitors. To establish the structureactivity relationship (SAR) of the compounds, 3D-QSAR techniques such as Comparative Molecular Field Analysis (CoMFA) and Comparative Molecular Similarity Indices Analysis (CoMSIA) were used.

The CoMFA $\left(q^{2}=0.774, r^{2}=0.965, \mathrm{ONC}=6\right.$, and $r^{2}$ pred $\left.=0.703\right)$ and CoMSIA $\left(q^{2}=0.676, r^{2}=\right.$ $0.949, \mathrm{ONC}=6$, and $r^{2}$ pred $=0.548$ ) both models have shown reasonable external predictive activity, and contour maps revealed favorable and unfavorable substitutions for chemical group modifications. Based on the contour maps, we have designed forty new compounds, among 
which, seven compounds exhibited higher predictive activity $\left(\mathrm{pIC}_{50}\right)$. Further, we conducted the MD study, ADME/Tox, and SA score prediction using the seven newly designed compounds. The combination of docking, MD, and 3D-QSAR studies helps to understand the coherence modification of existing molecules. Our study may provide valuable insight into the development of more potent ROCK1 inhibitors.

Keywords: Rho-associated kinase-1 (ROCK1); Cardiovascular disease; Molecular Docking; Molecular Dynamics; MMPBSA; 3D-QSAR; CoMFA; CoMSIA; ADME/Tox;

\section{Introduction}

Rho-associated kinase (ROCK) has been studied for its role as a downstream effector of small guanosine triphosphatases (GTPases), RhoA, RhoB, and RhoC ${ }^{1-2}$. It is a member of the serine/threonine AGC kinase family and phosphorylates various downstream targets such as myosin light chain 2 (MLC2), myosin light chain phosphatase 1 (MYPT1), LIM kinase, collapsing response mediator protein-2 (CRMP-2), adducin and calponin. The downstream phosphorylation promotes actin-myosin-mediated smooth muscle cell contraction, actin organization, cell proliferation, and migration ${ }^{3-6}$. ROCK 1 and ROCK2 are two isoforms of the ROCK family and consist of 1354 and 1388 amino acids, respectively. ROCK1 and ROCK2 share $65 \%$ overall sequence identity and $92 \%$ amino acid homology in their kinase domains as shown in Figure-1(a) ${ }^{7-8}$. Full-length ROCKs contain an N-terminal kinase domain, a coiled-coil linker region, and a Rho-binding domain (RBD). The split pleckstrin homology (PH) domain, containing a zink finger-like cysteine-rich tandem repeat $(\mathrm{ZF})$, is located at the $\mathrm{C}$-terminal end and shares $65 \%$ sequence identity between the two isoforms. The ROCKs exclusively interact with the switch-1 and switch-2 regions of the active RhoA, RhoB, and RhoC conjugated to GTP by their RBD domains ${ }^{9}$. However, ROCK 1 and ROCK2 have different binding preferences for membrane lipids. Their subcellular localizations were also found to be distinct. ROCK1 has been reported to have cytosolic localization and is closely associated with cell-cell adhesion, plasma membrane, and centrosomes, while ROCK2 is more abundant in the intercalated disk and Z-disk of striated muscle cells $\mathrm{s}^{3-4,10}$. In particular, ROCK1 regulates cell motility integrin $\beta 1$-activated focal adhesion kinase (FAK) signaling during multiple myeloma and lung cancer progression ${ }^{11-}$

12. Overexpression of ROCK1 is correlated with numerous pathophysiological conditions such as cardiac arrest, cerebral vasospasm, pulmonary hypertension, reperfusion injury, glaucoma, arteriosclerosis, Alzheimer's disease, and several types of cancer ${ }^{13-16}$. Thus, the pharmaceutical industry is focusing on the development of selective and nonselective ATP competitive ROCK inhibitors ${ }^{17}$. Figure-1(b) and (c) depicted the global structure of the ROCK1 kinase domain and an ATP competitive Type-1 inhibitor inside the binding pocket (PDB ID: 6E9W). The primary role of this inhibitor is to block the transmission of terminal phosphate from ATP to its corresponding substrate ${ }^{18}$. These inhibitors encompass a variety of chemical groups, such as pyridine, pyrazole, indazole, amino-furazan, and isoquinoline derivatives, which form critical interactions with the hinge loop at the binding pocket of kinase domain ${ }^{19-24}$. 
111 The computational modeling approach would play a viable role in the discovery of more potent

112 lead compounds as ROCK inhibitors. We have conducted a molecular modeling study of 42

113 novel N-ethyl-4-(pyridin-4-yl)benzamide-based compounds reported by Hobson et al. ${ }^{25}$, which

114 showed a wide range of inhibitory activity $\left(\mathrm{IC}_{50}=0.003 \mu \mathrm{M}-16 \mu \mathrm{M}\right)$ against $\mathrm{ROCK} 1$.

115 Compound C08, N-((2,3-Dihydrobenzo[b][1,4]dioxin-5-yl)methyl)-4-(pyridine-4-yl)benzamide

116 which was cocrystallized with ROCK1 (PDB ID: 6E9W), was selected as a representative

117 candidate among the compounds. To investigate the critical binding interaction, we performed

118 molecular docking and MD studies of C08, along with several other compounds in the dataset. In

119 addition, we have calculated the MMPBSA binding-free energy and interaction energy (IE) to

120 evaluate the binding affinity. Based on the average MD pose of C08, we developed the CoMFA

121 and CoMSIA models to establish the structure-activity (SAR) relationship. Finally, we designed

12240 new compounds and their activities $\left(\mathrm{pIC}_{50}\right)$ were predicted based on the CoMFA and

123 CoMSIA models. The designed compounds with higher $\mathrm{pIC}_{50}$ values were taken for the

124 Absorption Distribution Metabolism Excretion Toxicity (ADME/Tox), and Synthetic

125 Accessibility (SA) score analysis.

126

127

128

129

\section{Methodology}

\subsection{Molecular Docking}

130

Molecular docking experiments of the compounds C03, C08, C11, C13, C19, C22, C25, C29, C34, and C37 have been carried out using AutoDockTools (AutoDock 4.2, Scripps Research, CA, USA) as described by earlier studies ${ }^{26-27}$. The high-resolution crystal structure of ROCK1 (PDB ID:6E9W) was retrieved from the protein databank and used as a receptor in the docking study. Ligands and water molecules were removed from the original structure. The missing loop (residue S249-G253 and residue L372-T279) has been modeled with Modeller-10.1 (University of San Francisco, California, USA) and validated by Ramachandran plot analysis on the PROCHECK (DOE-MBI services, UCLA) server (Supplementary Figure-S1). The pyridinylbenzamide-based inhibitor, compound C08 in our dataset, is already available in the cocrystallized form. Therefore, $\mathrm{C} 08$ was treated as the most selective compound in our dataset. Compound $\mathrm{C} 34$ showed the highest inhibitory activity and was designated as the most active compound. Compounds C03, C11, C13, C19, C22, C25, C29, and C37 have different chemical subgroups in their positions $\mathrm{R}_{1}, \mathrm{R}_{2}, \mathrm{R}_{3}$ and $\mathrm{R}_{4}$ and exhibited a diverse range of activities against ROCK1, which were also included in the docking study. C08 was extracted and re-docked into the binding pocket of ROCK1. In brief, the protein was prepared by adding polar hydrogen and Kollman charges. The ligand was prepared by the addition of missing polar and nonpolar hydrogen atoms and assigned Gasteiger charges. To avoid excessive conformational explosions, the number of rotatable bonds was fixed to six. The AutoGrid program was used to define the grid box size of $50 \times 50 \times 60$ points in the $X, Y$, and $Z$ directions with the grid spacing of 0.375 , in such a way that it could conceal the entire ligand, while the grid center was set at $X=-65.0, Y=-$ 
151

152

153

154

155

156

157

158

159

160

161

162

163

164

165

166

167

168

169

170

171

172

173

174

175

176

177

178

179

180

181

182

183

184

185

186

187

188

100 docking runs were executed. The most suitable protein-ligand docking conformation was selected from the lowest binding energy with the lowest RMSD cluster of 100 runs. Polar, nonpolar, and hydrophobic interactions were also considered to evaluate the final protein-ligand binding pose. This docking protocol was repeated for compounds C03, C11, C13, C19, C22, C25, C29, and C37. Finally, the docking analysis was performed using AutoDockTools, PyMOL (Schrodinger, Inc.), and LigPlot+ (EMBL-EBI, Cambridgeshire, UK).

\subsection{MD simulation}

The MD simulations were run in GROMACS $2019.5^{28}$ using CHARMM36 all-atom Force Field (2020). The ligand topology and parameter files with partial charges were generated using the CHARMM General Force Field (CGenFF) (Massachusetts, USA). The protein-ligand docked complex was solvated with TIP3P water in a cubic periodic box model. The minimum distance between the protein and the box walls was maintained at $10 \AA$ in the $\mathrm{X}, \mathrm{Y}$, and $\mathrm{Z}$ directions. The $\mathrm{Na}^{+}$and $\mathrm{Cl}^{-}$counterions were added adequately to neutralize the system by replacing the solvent molecules. The entire system was subjected to energy minimization using the steepest descent integrator. Thereafter, the system was equilibrated for $200 \mathrm{ps}$ in the constant volume (NVT) ensemble to achieve the temperature of $300 \mathrm{~K}$, followed by $400 \mathrm{ps}$ in the constant pressure (NPT) ensemble to achieve 1 bar of pressure. The protein backbone was kept restrained during the NVT and NPT simulations. The particle mesh Ewald (PME) algorithm was used to deal with long-range electrostatic interactions and a cut-off value of $12 \AA$ was used to control the van der Waals interactions, respectively. The timestep was set to $2 \mathrm{fs}$. Finally, the production run has been continued from the NPT ensemble by unrestraining the protein backbone for $50 \mathrm{~ns}$. Temperature and pressure were controlled by the modified Berendsen thermostat (V-rescale) and the Parrinello-Rahman barostat. During the production run, the frames were collected at every 50 ps interval for further data analysis. RMSD, H-bonds, H-bond distance, and H-bond angle of each protein-ligand complex were calculated using the functions 'gmx rms', 'gmx hbond', 'gmx distance' and 'gmx angle' built in Gromacs. The simulation protocol was applied to all proteinligand complexes.

\subsection{MMPBSA binding free energy calculation}

The Molecular Mechanics Poison-Boltzmann Surface Area (MMPBSA) is a popular technique to calculate the binding-free energy between the protein and ligand. We have used the g_mmpbsa ${ }^{29}$ package to generate the MM/PBSA model of the protein-ligand complex, as described in the earlier stud ${ }^{30}$. After the total MMPBSA binding free energy was calculated, the residue-wise binding energy decomposition calculation was performed.

The binding-free energy from the MMPBSA method can be expressed as -

$\Delta G_{\text {bind }}$

$=\Delta G_{\text {complex }}-\Delta G_{\text {protein }}-\Delta G_{\text {ligand }}=\Delta E_{M M}+\Delta G_{\text {sol }}-T \Delta S=\Delta E_{v d W}+\Delta E_{\text {ele }}+$ $\Delta G_{G B}+\Delta G_{S A}-T \Delta S$ 
190

191

192

193

194

195

196

197

198

199

200

201

202

203

204

205

206

207

208

209

210

211

212

213

214

215

216

217

218

219

220

221

222

223

224

225

226

227

In which, the free energy of the protein-ligand complex was expressed by the $\Delta G_{\text {complex }}$. The binding energy of the protein and ligand in the solvent was expressed by $\Delta G_{\text {protein }}$ and $\Delta G_{\text {ligand }}$. The $\Delta E_{M M}$ represents the interaction energy between the protein and ligand in the gas phase condition, which was obtained by calculating the van der Waals energy $\left(\Delta E_{v d W}\right)$ and electrostatic energy $\left(\Delta E_{\text {ele }}\right)$. The $\Delta G_{\text {sol }}$ denote the free energy solvation which was derived by computing the polar solvation $\Delta G_{G B}$ and non-polar solvation $\Delta G_{S A}$ energy. Finally, $T \Delta S$ represents the entropy contribution during the ligand binding to its receptor. Due to the extensive computational process and relatively small impact on the final binding energy calculation, the $T \Delta S$ term was ignored in this study.

The interaction energy (IE) was calculated by 'gmx energy' function in Gromacs. The IE was estimated by combining the short-range Coulombic interaction (Coul-SR) and short-range Lennard Jones $(L J-S R)$ energy between the protein and ligand.

IE can be expressed as

$$
I E=\text { Coul-SR }+L J-S R
$$

\subsection{Dataset building and Molecular alignment}

In our current study, we have taken 42 novel pyridinyl-benzamide-based compounds which were reported as ROCK1 inhibitors. The inhibitory activity $\left(\mathrm{IC}_{50}\right)$ values, which were in $\mu \mathrm{M}$ units, were converted to $\log \mathrm{IC}_{50}\left(\mathrm{pIC}_{50}\right)$ values. The converted $\mathrm{pIC}_{50}$ values covered the activity range of $3 \log$ units $\left(\mathrm{pIC}_{50}=5.02\right.$ to 8.52$)$ for the 3D-QSAR study. The average structure of $\mathrm{C} 08$ from the last $1 \mathrm{~ns}$ MD trajectory, was taken as a representative compound from the dataset. Based on the structure of the reference molecule, the rest of the compounds were sketched, added hydrogen atoms, and calculated the Gasteiger-Hückel partial atomic charges in SYBYL-X 2.1 (Tripos Inc.) to build the dataset. These compounds were minimized using the tripos force field with a convergence of $0.05 \mathrm{kcal} / \mathrm{mol}$ by setting the maximum iteration to 2000 runs. The dataset molecules were further divided into the training set of 32 compounds to build the model and the test set of 9 compounds to evaluate the external predictivity of the 3D-QSAR model. Compound C16 has a nonspecific value and was excluded from the dataset during the 3D-QSAR study. Molecular alignment of the compounds is a vital step in 3D-QSAR, as it was assumed that, sharing the common scaffold, the compounds would bind to the receptor in a similar orientation $^{31}$. We have used the substructure-based alignment, distill-rigid fit, and database alignment functionality available in SYBYL-X 2.1. After that, the aligned compounds were subjected to the 3D-QSAR study.

\subsection{D-QSAR study}

CoMFA and CoMSIA are two routinely used 3D-QSAR methods to establish the structureactivity relationships of chemical compounds ${ }^{32-33}$. In both methods, the descriptors are calculated 
228

229

230

231

232

233

234

235

236

237

238

239

240

241

242

243

244

245

246

247

248

249

250

251

252

253

254

255

256

257

258

259

260

261

262

263

264

265

266

267

in a three-dimensional cubic lattice with $2 \AA$ grid spacing around the molecules. Steric (S) and electrostatic (E) fields were calculated separately for each molecule in CoMFA, by taking $S P^{3}$ carbon as a probe with a charge value of +1 and an energy tolerance cutoff of $30 \mathrm{kcal} / \mathrm{mol}$. The Lennard-Jones and Coulomb potential functions were used to calculate the steric and electrostatic fields, respectively. In the CoMSIA model, together with the steric and electrostatic fields, three additional descriptors such as hydrophobic $(\mathrm{H})$, hydrogen bond donor (D), and hydrogen bond acceptor (A) have been calculated. A Gaussian-type function was assigned to all grid points for calculating the similarity indices. The rest of the parameters were kept similar to the CoMFA.

\subsection{PLS calculation, CoMFA, and CoMSIA model building and validation}

The partial least squares (PLS) method was used to derive the statistically significant CoMFA and CoMSIA models, followed by the cross-validation $\left(q^{2}\right)$ and non-cross validation $\left(r^{2}\right)$ of the training set. In the PLS method, the $\mathrm{pIC}_{50}$ values (dependent variables) of the training set were correlated with their respective CoMFA and CoMSIA descriptor fields (independent variables). Leave-one-out (LOO) was used to obtain the cross-validation coefficient, $q^{2}$, the standard error of prediction (SEP), and the optimal number of components (ONC). Subsequently, a non-crossvalidated correlation coefficient, $r^{2}$, was generated for statistical indexing of the predictive power of the CoMFA and CoMSIA models along with the Fisher's statistics (F-value), standard error of estimation (SEE), and field contribution values of each descriptor. The column filtering value was set to $2.0 \mathrm{kcal} / \mathrm{mol}$ for both cross and non-cross validation methods. In CoMSIA, different combinations of descriptors ( $\mathrm{S}, \mathrm{E}, \mathrm{H}, \mathrm{A}$, and D) were used to obtain the best statistically significant model $^{34}$.

Sometimes, higher values of $q^{2}$ and $r^{2}$ may not be sufficient to evaluate the predictive outcomes of CoMFA and CoMSIA. Thus, the external predictive correlation coefficient $\left(r^{2}\right.$ pred $)$ was carried out to assess the predictive power of the models. The predictive correlation coefficient is expressed by the following equation:

$$
r_{p r e d}^{2}=(\text { SD-PRESS }) / \text { SD }
$$

SD stands for the sum of the squared deviation between the $\mathrm{pIC}_{50}$ values of the test set and the mean activity values of the training set. PRESS is the sum of the squared deviations between the observed and calculated activity values of each test set of compounds.

\subsection{Contour map analysis}

The CoMFA and CoMSIA result was represented as a StDev*Coeff contour map to visualize the field effect of the chemical descriptors around the most selective compound C08. The green and yellow contours represented the sterically favorable and unfavorable regions, while the blue and red contours represented the favorable substitution for positively or negatively charged chemical 
268

269

270

271

272

273

274

275

276

277

278

279

280

281

282

283

284

285

286

287

288

289

290

291

292

293

294

295

296

297

298

299

300

301

302

303

304

305

306

307

groups, respectively, in CoMFA and CoMSIA ${ }^{35}$. Likewise, the favorable and unfavorable positions of the hydrophobic, $\mathrm{H}$-bond acceptor and $\mathrm{H}$-bond donor were represented by yellowwhite, magenta-red, and purple-cyan by color scheme, respectively.

\subsection{New compound design, ADME/Tox, and synthetic accessibility prediction}

Based on the CoMFA and CoMSIA contour maps, we have designed forty new compounds and predicted their activity $\left(\mathrm{pIC}_{50}\right)$ by the CoMFA and CoMSIA models. Compounds with higher $\mathrm{pIC}_{50}$ values were subjected to docking, MD simulation, and MMPBSA analysis.

The newly designed compound has also proceeded with the ADME/Tox prediction and synthetic accessibility analysis by pkCSM ${ }^{36}$ (http://biosig.unimelb.edu.au/pkcsm) and SwissADMET ${ }^{37}$ (http://www.swissadme.ch) online web server.

\section{Results}

\subsection{Molecular docking analysis}

The reliability of the molecular docking was verified by the ligRMSD ${ }^{38}$ server, as the docking pose was further used in the MD study. The docked structures of ten compounds C03, C08, C11, C13, C19, C22, C25, C29, C34, and C37 were compared by aligning them with the C34 crystal pose (PDB ID: 6E9W). The final docked pose of each compound was selected based on the ECIDALs ${ }^{39}$ norms with an RMSD tolerance of $2 \AA$. The 1-(4-(pyridin-4-yl)phenyl)ethan-1-one scaffold of the docked compounds and crystal ligand was superimposed at the same position. The RMSD of each compound and their binding energy from the docking study were tabulated in Supplementary Table-S1. Except for compound C22 (RMSD = 2.89 $\AA$ ), the other compounds have shown the RMSD value of less than $2 \AA$ from the crystal ligand. The redocking of the $\mathrm{C} 08$ showed that it was stabilized by several polar and hydrophobic interactions in the active site. It formed the H-bond interaction with M156, located in the hinge loop, and another $\mathrm{H}$-bond interaction with the catalytic lysine K105. The Gatekeeper residue F368 formed the $\pi-\pi$ interaction with the pyrimidine ring. Other residues, such as I82, F87, A103, L107, Y155, formed the $\pi$-alkyl and hydrophobic interactions. When docking with the most active compound C34, an increased number of H-bonds was observed. Along with M156 and K105, residues R84 and F87 also participated in the H-bond interaction with C34 through their backbone hydroxyl ($\mathrm{OH}$ ) and amine (-NH2) groups. The detailed molecular docking interactions of compounds C08 and C34 have been illustrated in Figure-2. The 2D molecular docking interactions of the rest of the compounds C03, C11, C13, C19, C22, C25, C29, C37 were shown in Supplementary Figure-S2. Residues that participated in hydrophobic and H-bond interactions were shown in green and magenta colors, respectively, in Figure-2(a) and (d). The H-bond interactions were shown in red dotted lines in Figure-2(b) and (e). The active site cavity was shown by the hydrophobic surface model based on the Eisenberg scale in Figure-2(c) and (f), where white to red indicated the increase in hydrophobicity. All docked protein-ligand complexes were taken for the MD simulation study. 


\subsection{MD simulation analysis}

310

311

312

313

314

315

316

317

318

319

320

321

322

323

324

325

326

327

328

329

330

331

332

333

334

335

336

337

338

339

340

341

342

343

344

345

346

347

Since protein-ligand binding is a dynamic process, and a single docking result would have remained inconclusive. Therefore, we performed MD simulations for all ten protein-ligand complexes for $50 \mathrm{~ns}$. All systems were equilibrated within the initial $10 \mathrm{~ns}$ of simulation and thereafter maintained a stable plateau until the end of the run. The RMSD plot of each proteinligand system was shown in Supplementary Figure-S3. The fluctuation of RMSDs for the protein was observed within the range of 1.0-4.5 $\AA$, whereas the fluctuations of the ligands were found to be in the range of 0-3.0 $\AA$, respectively. To study the in-depth molecular interaction, we compared the binding pose from the MD trajectory (average structure taken from the final $1 \mathrm{~ns}$ ) and the docking pose of each compound by superimposing them. The morphed complexes were shown in Figure-3.

The conformations of compounds C03, C11, C19, C34, and C37 (Figure-3(a), (c), (e), (i), and (j)) from the MD simulation displayed close similarity with the corresponding binding pose from the docking study. The H-bond interactions with $\mathrm{K} 105$ and M156 remained intact until the final step of the trajectory. In contrast, compounds C08, C13, C25, and C29 (Figure-3(b), (d), (g), and (h)) lost the H-bond interaction between the carbonyl group ( $-\mathrm{C}=0)$ and $\mathrm{K} 105$. However, the H-bond interaction with the backbone nitrogen of M156 remained intact. In addition, compound $\mathrm{C} 25$ formed the H-bond interaction with the backbone nitrogen atom (N-atom) of R84 by the carbonyl group. For $\mathrm{C} 22$, which is the least active compound in the dataset, the two $\mathrm{H}$-bond interactions with K105 and M156 were found to be broken in the MD simulation analysis.

The overlapped structure (Figure-3(f)) showed that the distance between the hinge loop and the pyrimidine-2-amine ring of $\mathrm{C} 22$ increased and the methoxybenzene moiety was flipped outward from its docked position. However, C22 remained in the active site throughout the production run, mainly by forming polar and hydrophobic interactions with the surrounding residues. Because M156 is the key residue in forming the H-bond interaction, we examined the distance between the $\mathrm{N}$ atom of the M156 backbone and the $\mathrm{N}$ atom of the pyrimidine ring of the compounds throughout the simulation in Figure-4. Aside from C22, we found that the H-bond interaction distances from the residue M156 varied between 2-3.3 $\AA$ for other compounds. In the case of compound $\mathrm{C} 22$, the $\mathrm{H}$-bond interaction distance was increased to $\sim 4.9 \AA$. However, we did not see any major changes in the RMSD plot of C22 as observed in the Supplementary Figure-S3(f). One of the key precedents to determine the existence of the H-bond formation is the calculation of the angle between the donor hydrogen and acceptor (D-H-A) atoms, which was expected to be linear or close to $180^{\circ}$. Supplementary Figure-S4 depicted the distribution of the angle formation among the D-H-A atoms for each compound. Furthermore, we have calculated the relative frequency of the total number of H-bond interactions between ROCK1 and selected compounds in Supplementary Figure-S5. Throughout the production simulation, the frequency of H-bond interactions between ROCK1 and selected compounds was found to be in the range of 0 to 4. C19 and C22 showed a higher frequency of completely broken H-bond interactions ( $10 \%$ and $16 \%$, respectively) compared to other compounds.

Peerj reviewing PDF | (2021:05:61252:1:1:NEW 16 Jul 2021) 


\subsection{MMPBSA Binding energy and IE estimation}

350

351

352

353

354

355

356

357

358

359

360

361

362

363

364

365

366

367

368

369

370

371

372

373

374

375

376

377

378

379

380

381

382

383

384

385

386

387

We have calculated the MMPBSA binding-free energy and IE from the snapshots extracted from the final $2 \mathrm{~ns}$ of the MD trajectory of each system, to estimate the protein-ligand binding affinity. Electrostatic energy, van der Waals energy, and SASA energy terms were the main contributing factors to total BE. Alternatively, the short-range Coulombic (Coul-SR) interaction and the shortrange Lennard-Jones (LJ-SR) energy contributed to the total interaction energy. The details of MMPBSA binding free energy and IE were presented in Table-1. The total MMPBSA binding free energies were found to be $-107.85 \mathrm{~kJ} / \mathrm{mol},-109.22 \mathrm{~kJ} / \mathrm{mol},-114.08 \mathrm{~kJ} / \mathrm{mol},-102.36 \mathrm{~kJ} / \mathrm{mol}$, $76.09 \mathrm{~kJ} / \mathrm{mol},-95.44 \mathrm{~kJ} / \mathrm{mol},-123.18 \mathrm{~kJ} / \mathrm{mol},-108.85 \mathrm{~kJ} / \mathrm{mol},-130.61 \mathrm{~kJ} / \mathrm{mol},-106.69 \mathrm{~kJ} / \mathrm{mol}$ for compounds $\mathrm{C} 03, \mathrm{C} 08, \mathrm{C} 11, \mathrm{C} 13, \mathrm{C} 19, \mathrm{C} 22, \mathrm{C} 25, \mathrm{C} 29, \mathrm{C} 34$ and $\mathrm{C} 37$, respectively. The IE was found to be $-253.41 \mathrm{~kJ} / \mathrm{mol},-247.97 \mathrm{~kJ} / \mathrm{mol},-279.69 \mathrm{~kJ} / \mathrm{mol},-194.26 \mathrm{~kJ} / \mathrm{mol},-215.37 \mathrm{~kJ} / \mathrm{mol}$, $210.93 \mathrm{~kJ} / \mathrm{mol},-284.75 \mathrm{~kJ} / \mathrm{mol},-226.21 \mathrm{~kJ} / \mathrm{mol},-284.21 \mathrm{~kJ} / \mathrm{mol},-233.93 \mathrm{~kJ} / \mathrm{mol}$ for the compounds C03, C08, C11, C13, C19, C22, C25, C29, C34 and C37, respectively. The most active compound, $\mathrm{C} 34$ resulted in the lowest binding-free energy in the MMPBSA model. In addition, with $\mathrm{C} 25, \mathrm{C} 34$ provided the lowest IE values among the other compounds. However, we did not find any correlation between the $\mathrm{pIC}_{50}$ and MMPBSA or IE values. The common residues, which contributed to the noticeable amount of net positive and net negative BE energy were shown in Supplementary Table-S2. The graphical comparison of BE decomposition by these residues was shown in Figure-5. Residues E89, V90, E124, D126, Y155, D160, D202 contributed the lowest BE, while residues K105 and R125 contributed the highest BE to the ligands. However, we observed a large variation in BE decomposition by residue D216. In the formation of the complex with $\mathrm{C} 03, \mathrm{C} 11, \mathrm{C} 25$, and $\mathrm{C} 34$, it provided net positive $\mathrm{BE}$ values in the total binding energy. Conversely, it contributed negative BE in compounds C08, C13, C19, C22, C29, and C37, respectively.

\subsection{Molecular alignment and 3D-QSAR studies}

The coherence selection of the compounds and the splitting of them into a training set and a test set is an important step toward the development of the 3D-QSAR. The dataset compounds and their corresponding $\mathrm{pIC}_{50}$ values were shown in Table-2. We classified the compounds into high, medium, and low activity ranges and chose the test set compounds so that they can cover different activity values while maintaining structural variations. All training set compounds were aligned to the representative compound $\mathrm{C} 08$ by their common substructure $\mathrm{N}$ -

isopropylbenzamide. The aligned compounds and their common substructure has been illustrated in Supplementary Figure-S6.

We have produced the CoMFA and CoMSIA models based on the 32 compounds in the training set. For model validation, we have restricted the statistical parameters of $q^{2}>0.6 ; r^{2}>0.8$ and $r^{2}{ }_{p r e d}>0.5$. Initially, we applied different charge fields, namely, Gasteiger, Gasteiger-Hückle, Pullman, MMFF94 charges, to obtain the best possible CoMFA model. In the cross-validated model, we obtained the final $q^{2}=0.774$, an ONC value of 6 , and a SEP value of 0.425 in the

Peerj reviewing PDF | (2021:05:61252:1:1:NEW 16 Jul 2021) 
388 Gasteiger charge field. In the non-cross-validated model, the $r^{2}$ value and the SEE value were

389

390

391

392

393

394

395

396

397

398

399

400

401

402

403

404

405

406

407

408

409

410

411

412

413

414

415

416

417

418

419

420

421

422

423

424

425

426

427

found to be 0.965 and 0.167 , respectively. We have employed the same charge to build a reliable CoMSIA model with multiple combinations of steric (S), electrostatic (E), hydrophobic (H), and $\mathrm{H}$-bond acceptor (A) and H-bond donor (D) fields.

Only the steric and electrostatic field produced a reasonable CoMSIA model with $q^{2}=0.676$ and $\mathrm{ONC}=6$ from cross-validation and $r^{2}=0.949$ from non-cross-validation, respectively. The $r^{2}{ }_{\text {pred }}$ of CoMFA and CoMSIA (SE) was found to be 0.703 and 0.548 , which is higher than the set criteria of 0.5. Overall, both CoMFA and CoMSIA exhibited the robustness of the external predictivity. The detailed statistics of the 3D-QSAR statistics were shown in Table-3. The statistics of the different combinations of descriptors in the CoMSIA model have been tabulated in Supplementary Table-S3. The actual $\mathrm{pIC}_{50}$ and predicted $\mathrm{pIC}_{50}$ from CoMFA and CoMSIA with their residuals were shown in the Supplementary Table-S4.

\subsection{CoMFA and CoMSIA contour map and SAR analysis}

From the 3D-QSAR study, we have plotted the correlation plots between the actual pIC50 and the predicted $\mathrm{pIC}_{50}$ in Figure-6. The compounds in the training and test sets have been labeled dark and light green, respectively. The contour maps generated by CoMFA and CoMSIA around the compound $\mathrm{C} 08$ are shown in Figures-6(b), (c), (e), and (f). From the CoMFA model, we obtained the steric and electrostatic field contributions of $63 \%$ and $37 \%$, respectively, and from the CoMSIA model, we found the steric and electrostatic field contribution of $57.2 \%$ and $42.8 \%$, respectively. A green contour map indicates a favorable substitution for the bulky steric groups, whereas a yellow contour indicates that the steric substitution would be unfavorable. Similarly, a blue and red contours represent favorable and unfavorable substitutions for positively charged electron-donating groups, respectively, to increase the inhibitory activity of the molecules. The green contour was observed at position $\mathrm{R}_{4}$ (Figure-6(b) and (e)) near F120, which indicated that the steric groups could be favorable at that position. Compounds C25 and C26 with a propylpyrrolidine moiety at the $\mathrm{R}_{4}$ position exhibited higher activity values than Compounds $\mathrm{C} 01-\mathrm{C} 04$ and $\mathrm{C} 08-\mathrm{C} 11$ with smaller groups present at their $\mathrm{R}_{4}$ position. A green contour at the $\mathrm{R}_{3}$ position near residue $\mathrm{V} 90$ also indicated a favorable substitution for the steric groups. The yellow contours were observed near the M156 position in R2 and near the R84 residue in $\mathrm{R}_{1}$ position in the CoMFA model, which represented the unfavorable position for steric substitution. The contour maps suggested that a steric group would be unfavorable for $\mathrm{R}_{2}$ substitution. This could be the reason why compounds C34, C36, and C25-27 had higher activities than C20-24. Figure-5(c) and (f) show a blue contour covering the dioxane ring at the $\mathrm{R}_{1}$ position, and two red contours near K105 and R84, indicating that the electron-donating and electron-accepting group replacement may increase the effectiveness of the inhibitors.

\subsection{Designing of new compounds}

Based on the CoMFA and CoMSIA contour map analysis, we have acquired an ideal scheme to design a more potent ROCK1 inhibitor drawn in Figure-7, based on compound 08. A steric and

Peerj reviewing PDF | (2021:05:61252:1:1:NEW 16 Jul 2021) 
428

429

430

431

432

433

434

435

436

437

438

439

440

441

442

443

444

445

446

447

448

449

450

451

452

453

454

455

456

457

458

459

460

461

462

463

464

465

466

467

an electropositive group would be preferred for the $\mathrm{R}_{2}$ and $\mathrm{R}_{4}$ positions. A steric-electropositive group at the $\mathrm{R}_{3}$ position could increase the activity of existing compounds. As the CoMFA scheme showed higher statistical significance $\left(q^{2}\right.$ and $\left.r^{2}\right)$ and predictive power $\left(r_{\text {pred }}^{2}\right)$, the designed compounds were evaluated by the CoMFA model. Based on the scheme in Figure-7, we have designed forty new compounds and predicted their activity values in the CoMFA model , Supplementary Table-S5. Of these, seven designed compounds, D02, D03, D06, D31, D32, D33, D35, have exhibited higher $\mathrm{pIC}_{50}$ values than the most active compound $\mathrm{C} 34$, as shown in Table-4. We have utilized the pkCSM and SwissADME server to analyze the ADME/Tox and SA scores. For comparison, we have also taken the compounds C08, C34, and C37 from the dataset. The detailed analysis has been tabulated in Supplementary Table-S6. Except for compound D06, none of the designed compounds showed AMES toxicity. The SA score predicts the synthetic accessibility of small molecules. A SA score of 1 denotes the ease of synthesis and an SA score of 10 expresses the difficulty of synthesizing the chemical compound. The SA score of the designed compound was predicted to be less than 5, which stated that the compounds would have a low to moderate difficulty in the synthesis routes. We have also examined the docking (Supplementary Table-S7) and MD studies on these seven newly designed compounds to estimate their binding interaction. The RMSD graph was shown in Supplementary FigureS7. The MMPBSA and the interaction energy were shown in Table-5. The residue-wise binding energy decomposition was shown in Supplementary Table-S9. The catalytic lysine K105 has exhibited a higher positive binding energy decomposition among the selected residues. Finally, we have taken the last $1 \mathrm{~ns}$ average structure of the protein and designed ligand complexes to study the key interactions at the residue level. The designed compounds tend to form a higher number of H-bond interactions with the surrounding residues compared to the dataset compounds. The in-depth interactions in the active site pocket were illustrated in Figure-8.

\section{Discussion}

Together with the docking study, the CoMFA and CoMSIA contour maps provided a valuable insight into the rational modifications of existing compounds. The data were shown in

Supplementary Table-S1 and Table-S7 from ligRMSD, which has provided the validity of our docking protocol for both the existing compounds and designed compounds. One of the key $\mathrm{H}$ bond interactions was between the M156 residue and the N atom of the pyrimidine ring, which played a crucial role in anchoring the ligands. The surrounding residues were found to be M153, A215, Y155, A103, V90, F120, and F87, which formed the hydrophobic surface. In CoMFA study, a yellow contour was observed near the hinge loop, which suggested that the compound having a steric group might not be favorable. A small blue contour was observed near the backbone of Y155, suggesting that a small electron donor would be advantageous at that site. From the docking and MD study, we have observed that C22, which has a 2-methyl-1(methylamino) propan-2-ol group with the pyrimidine moiety, prevents the formation of $\mathrm{H}$ bonds with M156 and resulted in the loss of the H-bond interaction. This may affect the inhibitory activity of compound $\mathrm{C} 22$. For the same reason, having a steric group on the pyrimidine ring, 
468 C21, C23, and C24 might have decreased inhibitory activity. Another key H-bond interaction

469

470

471

472

473

474

475

476

477

478

479

480

481

482

483

484

485

486

487

488

489

490

491

492

493

494

495

496

497

498

499

500

501

502

503

504

505

506

507 was detected between the $\mathrm{K} 105$ and the $-\mathrm{C}=\mathrm{O}$ groups of the docked compounds. Due to the presence of a rotatable bond (torsion) in the molecules, this H-bond formation might occasionally get interrupted. At the $\mathrm{R}_{3}$ position, a large green contour suggested that a bulky steric group will be beneficial. However, our docking and MD studies suggested that substitution for the larger groups could be limited. Similarly, a larger substitution of the steric group at the $\mathrm{R}_{4}$ position might result in a steric clash with the surrounding residues. Therefore, we have chosen the major modification strategies at the positions $\mathrm{R}_{3}$ and $\mathrm{R}_{4}$ when designing the new compounds. The introduction of chemical group substitution at the positions $R_{3}$ and $R_{4}$ increased the probability of H-bond formation with either D160 or I82, which led to the higher binding affinity of the newly designed compounds to ROCK1. The RMSD graphs of the newly designed compounds indicated stable protein-ligand complexes. We have calculated the angular distributions and distances among the D-H-A atoms of M156 and the newly designed compounds in Supplementary Figure-S8 and Figure-S9, respectively. Finally, the average Hbond angle values and distances of the dataset compounds and designed compounds were summarized in Supplementary Table-S8. The distance between the H-bond donor and acceptor atoms was found to be less than $5 \AA$, and the angle values were found to be within the range of $120^{\circ}-180^{\circ}$. This configuration suggests a reasonable geometry for a stable H-bond interaction. In the MMPBSA energy evaluation, the vdW energy and the electrostatic energy added the key energy values in total BE. Nonethless, negative SASA scores also favored total binding energy. In Figure-9 below, we have shown a comparative plot of the decomposition of the MMPBSA binding energy to the designed compounds. Residues with net negative binding energy contribution and net positive energy contribution were shown in slate and magenta colors. Residues K105, R125, and K200 have been found to contribute a positive energy value to the total binding energy of the designed compounds. Residues E89, V90, E124, D202, L205, and F368 contributed to negative binding energy decomposition.

Prior to the commencement of the experimental procedure, the prediction of the pharmacokinetic properties and bioavailability of the designed compounds is necessary. The prediction of ADME/Tox showed the high gastrointestinal absorption of the designed compounds, which indicated that the compound would have good bioavailability. The inhibitory effects of the designed compounds on different types of Cytochrome P450 were marked by Yes/No representation and possibly excreted through biotransformation. In general, the ADME/Tox analysis predicted that the designed compound would be a safer and more active ROCK1 inhibitor.

\section{Conclusions}

The discovery of a potent ROCK1 inhibitor is a promising strategy to achieve the therapeutic goal against cardiovascular disease and carcinomas. In our present study, we have performed the molecular modeling study of 41 pyridinyl-benzamide-based ROCK1 inhibitors. Molecular docking, Molecular Dynamics, MMPBSA, and IE calculations provide critical information about

Peer) reviewing PDF | (2021:05:61252:1:1:NEW 16 Jul 2021) 
508 the molecular interactions and binding affinity between protein-inhibitor complexes. We have 509 established a reasonable correlation between the actual and predictive activity of the compounds

510 from the CoMFA and CoMSIA models with external predictive capability. The contour maps

511 from the CoMFA and CoMSIA described the structure-activity relationship of the compounds.

512 Models also suggest that it could predict the activity of the newly designed compound with a

513 similar scaffold. Based on the SAR study, we have designed several new compounds, and seven

514 of them expressed higher $\mathrm{pIC}_{50}$ values compared to the most active compound C34. Estimation

515 of ADME/Tox and SA scores suggested that the designed compounds would have more potent

516 inhibitory activity against ROCK1 while having the desirable pharmacokinetics property and

517 bioavailability. Additionally, we have validated our results with the selected designed

518 compounds by MD simulation, MMPBSA, and IE models. The outcome of our study might be

519 useful to the future development of the ROCK1 inhibitor.

520

521

\section{Author Contributions}

522 S.G: S.K and S.J.C conceptualized and designed the project. S.G and S.K performed the

523 experiments, data analysis, and figure making and wrote the manuscript. S.J.C superintended the

524

525

526 project. All authors discussed the work and remarked on this manuscript.

\section{Acknowledgments}

527 The authors are thankful to the academic editor and reviewers for their valuable feedback, which

528 has improved the quality of the manuscript, and want to acknowledge the Chosun University for 529 financial support.

530

531

532

533

\section{References}

534

535

536

537

538

539

540

1. Tang, A. T.; Campbell, W. B.; Nithipatikom, K., ROCK1 feedback regulation of the upstream small GTPase RhoA. Cellular signalling 2012, 24 (7), 1375-1380.

2. Vigil, D.; Kim, T. Y.; Plachco, A.; Garton, A. J.; Castaldo, L.; Pachter, J. A.; Dong, H.; Chen, X.; Tokar, B.; Campbell, S. L., ROCK1 and ROCK2 are required for non-small cell lung cancer anchorageindependent growth and invasion. Cancer research 2012, 72 (20), 5338-5347.

3. Lock, F. E.; Ryan, K. R.; Poulter, N. S.; Parsons, M.; Hotchin, N. A., Differential regulation of adhesion complex turnover by ROCK1 and ROCK2. PloS one 2012, 7 (2), e31423.

541 4. Shi, J.; Wu, X.; Surma, M.; Vemula, S.; Zhang, L.; Yang, Y.; Kapur, R.; Wei, L., Distinct roles for

542 ROCK1 and ROCK2 in the regulation of cell detachment. Cell death \& disease 2013, 4 (2), e483-e483.

$5435 . \quad$ Sunamura, S.; Satoh, K.; Kurosawa, R.; Ohtsuki, T.; Kikuchi, N.; Elias-Al-Mamun, M.; Shimizu, T.;

544 Ikeda, S.; Suzuki, K.; Satoh, T., Different roles of myocardial ROCK1 and ROCK2 in cardiac dysfunction and

545 postcapillary pulmonary hypertension in mice. Proceedings of the National Academy of Sciences 2018,

546115 (30), E7129-E7138.

547 6. Kalaji, R.; Wheeler, A. P.; Erasmus, J. C.; Lee, S. Y.; Endres, R. G.; Cramer, L. P.; Braga, V. M.,

548 ROCK1 and ROCK2 regulate epithelial polarisation and geometric cell shape. Biology of the Cell 2012,

$549104(8), 435-451$. 
$5507 . \quad J u d g e$, R. A.; Vasudevan, A.; Scott, V. E.; Simler, G. H.; Pratt, S. D.; Namovic, M. T.; Putman, C. B.; 551 Aguirre, A.; Stoll, V. S.; Mamo, M., Design of Aminobenzothiazole Inhibitors of Rho Kinases 1 and 2 by 552 Using Protein Kinase A as a Structure Surrogate. ChemBioChem 2018, 19 (6), 613-621.

553 8. Heikkila, T.; Wheatley, E.; Crighton, D.; Schroder, E.; Boakes, A.; Kaye, S. J.; Mezna, M.; Pang, L.; 554 Rushbrooke, M.; Turnbull, A., Co-crystal structures of inhibitors with MRCK $\beta$, a key regulator of tumor 555 cell invasion. PLoS One 2011, 6 (9), e24825.

556 9. Hartmann, S.; Ridley, A. J.; Lutz, S., The function of Rho-associated kinases ROCK1 and ROCK2 in the pathogenesis of cardiovascular disease. Frontiers in pharmacology 2015, 6, 276. 559 H.-H.; Destaing, O.; Mertani, H., The CCM1-CCM2 complex controls complementary functions of ROCK1 and ROCK2 that are required for endothelial integrity. Journal of cell science 2018, 131 (15).

11. Amit, C.; Padmanabhan, P.; Elchuri, S. V.; Narayanan, J., Probing the effect of matrix stiffness in endocytic signalling pathway of corneal epithelium. Biochemical and biophysical research communications 2020, 525 (2), 280-285.

12. Gilkes, D. M.; Xiang, L.; Lee, S. J.; Chaturvedi, P.; Hubbi, M. E.; Wirtz, D.; Semenza, G. L., Hypoxiainducible factors mediate coordinated RhoA-ROCK1 expression and signaling in breast cancer cells. Proceedings of the National Academy of Sciences 2014, 111 (3), E384-E393.

13. Jin, Z.; Jiang, S.; Jian, S.; Shang, Z., Long noncoding RNA MORT overexpression inhibits cancer cell proliferation in oral squamous cell carcinoma by downregulating ROCK1. Journal of cellular biochemistry 2019, 120 (7), 11702-11707.

14. Shi, J.; Zhang, Y.-W.; Yang, Y.; Zhang, L.; Wei, L., ROCK1 plays an essential role in the transition from cardiac hypertrophy to failure in mice. Journal of molecular and cellular cardiology 2010, 49 (5), 819-828.

15. Shao, J.; Welch, W. J.; DiProspero, N. A.; Diamond, M. I., Phosphorylation of profilin by ROCK1 regulates polyglutamine aggregation. Molecular and cellular biology 2008, 28 (17), 5196-5208.

16. Hu, Y.-B.; Zou, Y.; Huang, Y.; Zhang, Y.-F.; Lourenco, G. F.; Chen, S.-D.; Halliday, G. M.; Wang, G.; Ren, R.-J., ROCK1 is associated with Alzheimer's Disease-specific plaques, as well as enhances autophagosome formation but not autophagic $A \beta$ clearance. Frontiers in cellular neuroscience 2016, 10 , 253.

17. Feng, Y.; LoGrasso, P. V.; Defert, O.; Li, R., Rho kinase (ROCK) inhibitors and their therapeutic potential. Journal of medicinal chemistry 2016, 59 (6), 2269-2300.

18. Koch, J. C.; Tatenhorst, L.; Roser, A.-E.; Saal, K.-A.; Tönges, L.; Lingor, P., ROCK inhibition in models of neurodegeneration and its potential for clinical translation. Pharmacology \& therapeutics 2018, 189, 1-21.

19. Feng, Y.; Cameron, M. D.; Frackowiak, B.; Griffin, E.; Lin, L.; Ruiz, C.; Schröter, T.; LoGrasso, P., Structure-activity relationships, and drug metabolism and pharmacokinetic properties for indazole piperazine and indazole piperidine inhibitors of ROCK-II. Bioorganic \& medicinal chemistry letters 2007, $17(8), 2355-2360$.

20. Goodman, K. B.; Cui, H.; Dowdell, S. E.; Gaitanopoulos, D. E.; Ivy, R. L.; Sehon, C. A.; Stavenger, R. A.; Wang, G. Z.; Viet, A. Q.; Xu, W., Development of dihydropyridone indazole amides as selective Rhokinase inhibitors. Journal of medicinal chemistry 2007, 50 (1), 6-9.

21. Abbhi, V.; Saini, L.; Mishra, S.; Sethi, G.; Kumar, A. P.; Piplani, P., Design and synthesis of benzimidazole-based Rho kinase inhibitors for the treatment of glaucoma. Bioorganic \& medicinal chemistry 2017, 25 (21), 6071-6085.

22. Schirok, H.; Kast, R.; Figueroa-Pérez, S.; Bennabi, S.; Gnoth, M. J.; Feurer, A.; Heckroth, H.; Thutewohl, M.; Paulsen, H.; Knorr, A., Design and Synthesis of Potent and Selective Azaindole-Based Rho Kinase (ROCK) Inhibitors. ChemMedChem: Chemistry Enabling Drug Discovery 2008, 3 (12), 1893-1904. 
597 23. Fang, X.; Yin, Y.; Chen, Y. T.; Yao, L.; Wang, B.; Cameron, M. D.; Lin, L.; Khan, S.; Ruiz, C.; Schröter,

598 T., Tetrahydroisoquinoline derivatives as highly selective and potent Rho kinase inhibitors. Journal of

599 medicinal chemistry 2010, 53 (15), 5727-5737.

600 24. Gingras, K.; Avedissian, H.; Thouin, E.; Boulanger, V.; Essagian, C.; McKerracher, L.; Lubell, W. D.,

601 Synthesis and evaluation of 4-(1-aminoalkyl)-N-(4-pyridyl) cyclohexanecarboxamides as Rho kinase

602 inhibitors and neurite outgrowth promoters. Bioorganic \& medicinal chemistry letters 2004, 14 (19),

603 4931-4934.

604 25. Hobson, A. D.; Judge, R. A.; Aguirre, A. L.; Brown, B. S.; Cui, Y.; Ding, P.; Dominguez, E.;

605 DiGiammarino, E.; Egan, D. A.; Freiberg, G. M., Identification of selective dual ROCK1 and ROCK2

606 inhibitors using structure-based drug design. Journal of medicinal chemistry 2018, 61 (24), 11074-11100.

607 26. Keretsu, S.; Bhujbal, S. P.; Cho, S. J., Computational study of paroxetine-like inhibitors reveals

608 new molecular insight to inhibit GRK2 with selectivity over ROCK1. Scientific reports 2019, 9 (1), 1-14.

609 27. Keretsu, S.; Bhujbal, S. P.; Cho, S. J., Docking and 3D-QSAR Studies of Hydrazone and Triazole

610 Derivatives for Selective Inhibition of GRK2 over ROCK2. Letters in Drug Design \& Discovery 2020, 17 (5),

$611618-632$.

612 28. Lindahl, E.; Abraham, M.; Hess, B.; van der Spoel, D., GROMACS 2020 Manual. Version: 2020.

613 29. Kumari, R.; Kumar, R.; Consortium, O. S. D. D.; Lynn, A., g_mmpbsa? A GROMACS tool for high-

614 throughput MM-PBSA calculations. Journal of chemical information and modeling 2014, 54 (7), $1951-$

6151962.

616 30. Keretsu, S.; Ghosh, S.; Cho, S. J., Molecular Modeling Study of c-KIT/PDGFR $\alpha$ Dual Inhibitors for

617 the Treatment of Gastrointestinal Stromal Tumors. International journal of molecular sciences 2020, 21

618 (21), 8232.

619 31. Bang, S. J.; Cho, S. J., Comparative molecular field analysis (CoMFA) and comparative molecular 620 similarity index analysis (CoMSIA) study of mutagen X. BULLETIN-KOREAN CHEMICAL SOCIETY 2004, 25

621 (10), 1525-1530.

622 32. Gadhe, C. G.; Madhavan, T.; Kothandan, G.; Cho, S. J., In silico quantitative structure-activity

623 relationship studies on $\mathrm{P}$-gp modulators of tetrahydroisoquinoline-ethyl-phenylamine series. BMC

624 structural biology 2011, 11 (1), 5.

625 33. Pasha, F.; Cho, S. J.; Beg, Y.; Tripathi, Y., Quantum chemical QSAR study of flavones and their 626 radical-scavenging activity. Medicinal Chemistry Research 2007, 16 (7-9), 408-417.

627 34. San Juan, A. A.; Cho, S. J., 3D-QSAR study of microsomal prostaglandin E 2 synthase (mPGES-1) 628 inhibitors. Journal of Molecular Modeling 2007, 13 (5), 601-610.

629 35. Gadhe, C. G.; Kothandan, G.; Cho, S. J., Large variation in electrostatic contours upon addition of

630 steric parameters and the effect of charge calculation schemes in CoMFA on mutagenicity of MX

631 analogues. Molecular Simulation 2012, 38 (11), 861-871.

632 36. Pires, D. E.; Blundell, T. L.; Ascher, D. B., pkCSM: predicting small-molecule pharmacokinetic and

633 toxicity properties using graph-based signatures. Journal of medicinal chemistry 2015, 58 (9), $4066-4072$.

634 37. Daina, A.; Michielin, O.; Zoete, V., SwissADME: a free web tool to evaluate pharmacokinetics,

635 drug-likeness and medicinal chemistry friendliness of small molecules. Scientific reports 2017, 7 (1), 1-

63613.

637 38. Velázquez-Libera, J. L.; Durán-Verdugo, F.; Valdés-Jiménez, A.; Núñez-Vivanco, G.; Caballero, J.,

638 LigRMSD: a web server for automatic structure matching and RMSD calculations among identical and

639 similar compounds in protein-ligand docking. Bioinformatics 2020, 36 (9), 2912-2914.

640 39. Muñoz-Gutierrez, C.; Adasme-Carreño, F.; Fuentes, E.; Palomo, I.; Caballero, J., Computational

641 study of the binding orientation and affinity of PPAR $y$ agonists: Inclusion of ligand-induced fit by cross-

642 docking. Rsc Advances 2016, 6 (69), 64756-64768.

643 


\section{Figure 1}

Domain maps and X-ray structure of human ROCK1 protein

a) ROCK1 and ROCK2 isoforms share $64 \%$ overall sequence identity. The highest homology of $92 \%$, was found in the $\mathrm{N}$-terminal kinase domain. Both the isoforms can be activated when binding with the RhoGTP by their Rho-binding domain (RBD). Additionally, ROCK1 consists of an HR domain in its coiled-coil region, which binds to RhoA. The zink finger-like domain (ZFD) is located at the C-terminal pleckstrin homology domain (PHD) in both the isoforms. The heptagonal blue $\mathrm{P}$ signs are indicating the different phosphorylation sites. b) N-lobe, C-lobe, Activation loop, P-loop, ATP binding site, and Hinge loop were shown in different color schemes by surface model and cartoon representation. c) Global structure of the inhibitor bound ROCK1 showing the ATP pocket, phosphorylation site, catalytic loop, HRD, and DFG motif. 
a)

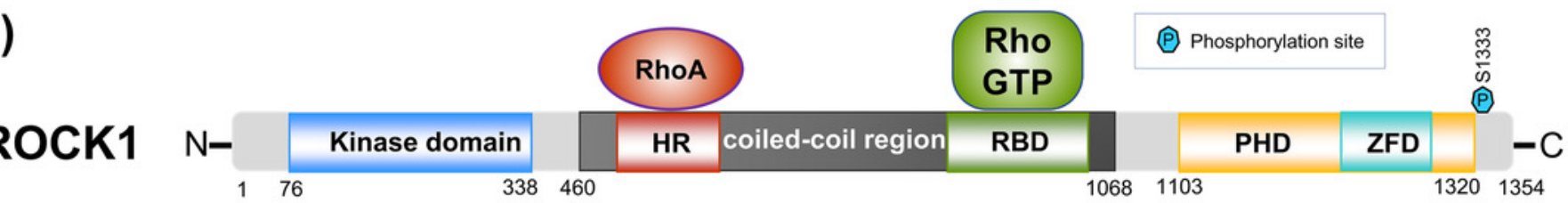

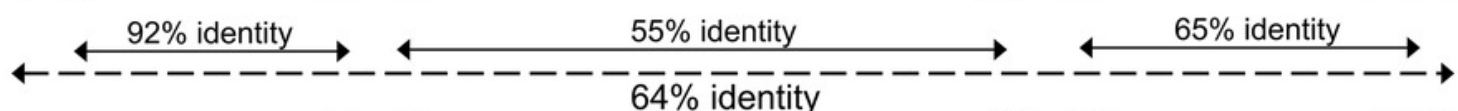

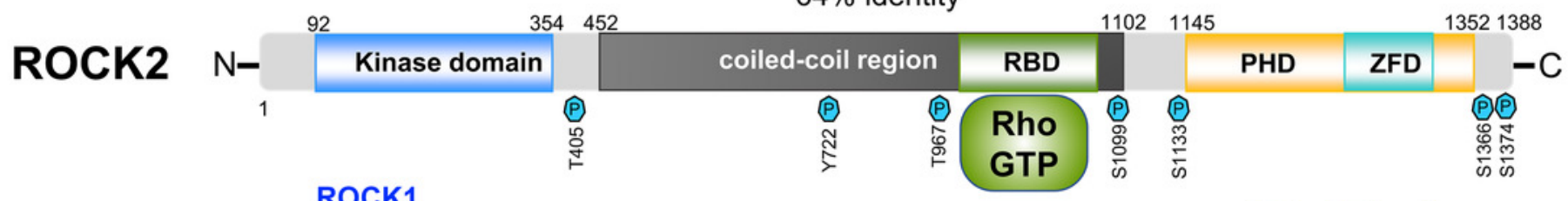

b)

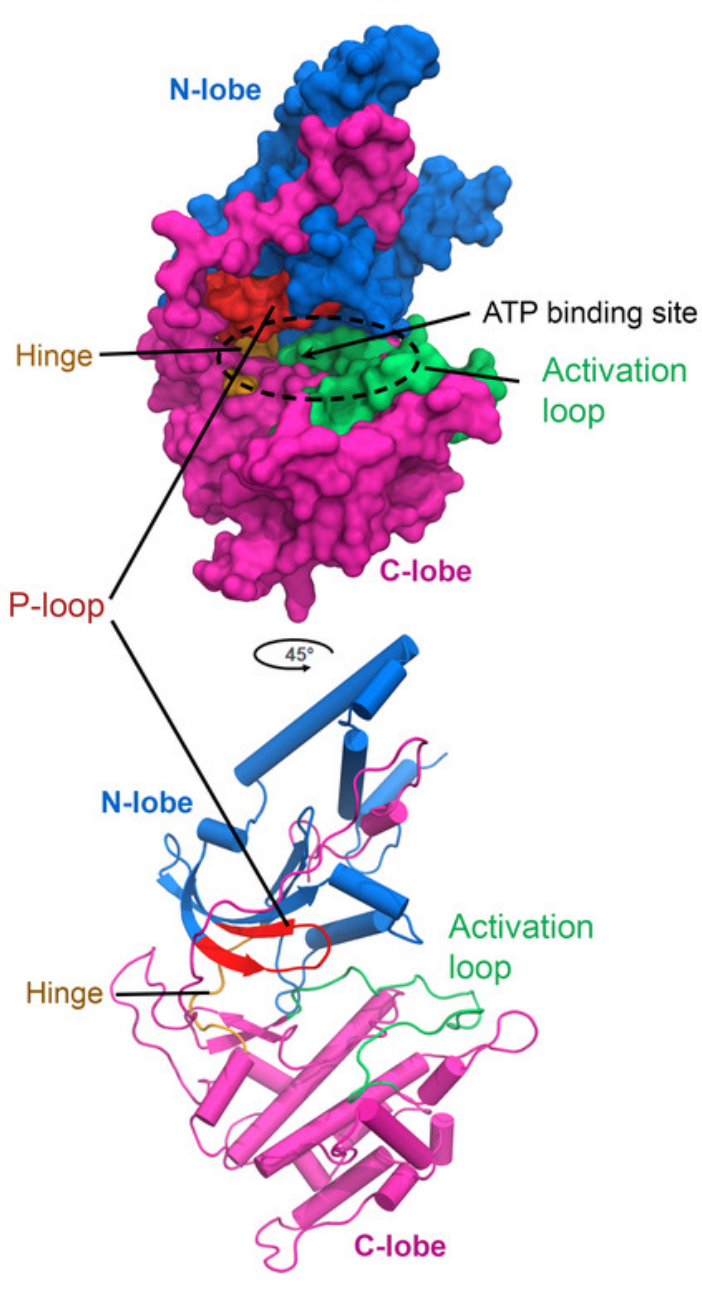

c)

ATP-competitive

B3

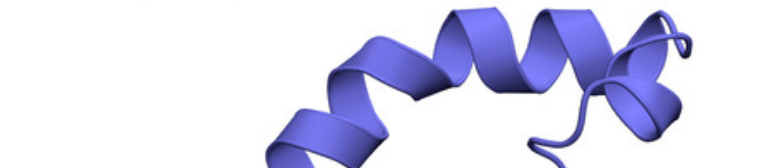
inhibitor

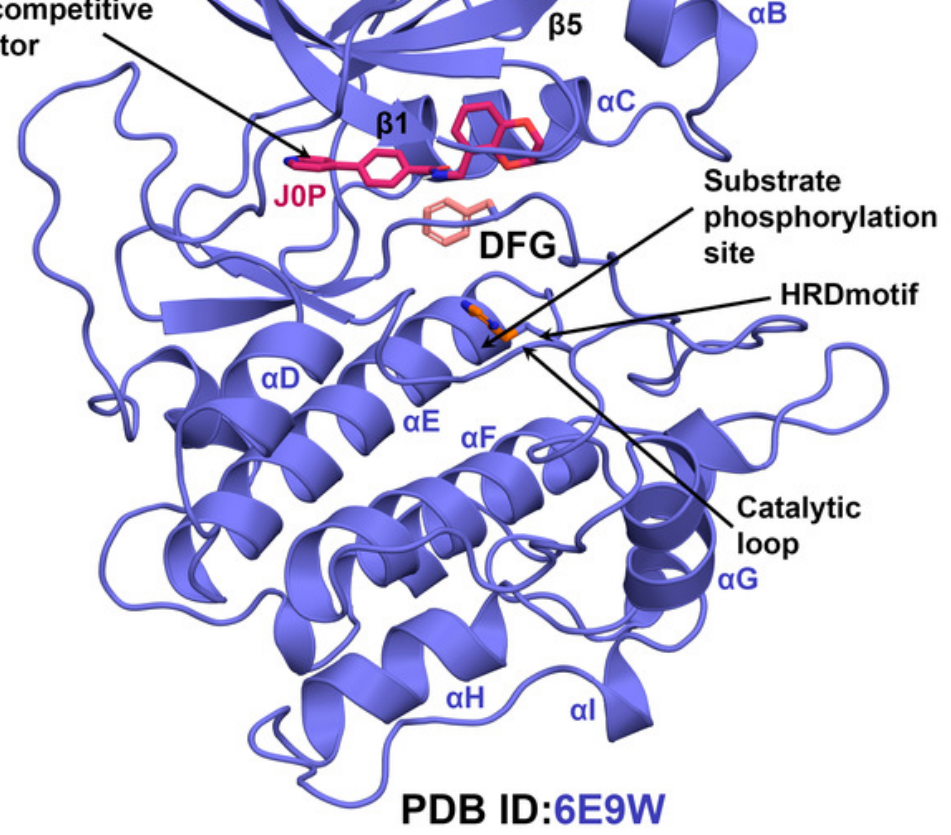




\section{Figure 2}

Molecular Docking analysis of compounds C08 and C34 with ROCK1

a) Docking interaction of $\mathrm{C0} 8$ in 2D representation. b) $\mathrm{H}$-bond formation of $\mathrm{C0} 8$ in the binding pocket. c) C08 surrounded by hydrophobic residues. d) Docking interaction of C34 in 2D representation. e) $\mathrm{H}$-bond formation of C34 in the active site cavity. f) C34 surrounded by hydrophobic residues. The low $(\mathrm{L})$ to high $(\mathrm{H})$ hydrophobicity was represented by a white to red color scheme. $\mathrm{H}$-bonds have been shown in red dashed lines.

a)

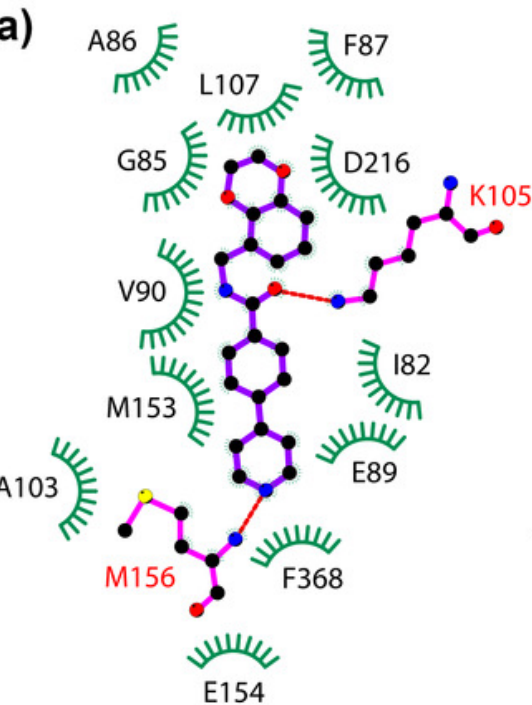

d)

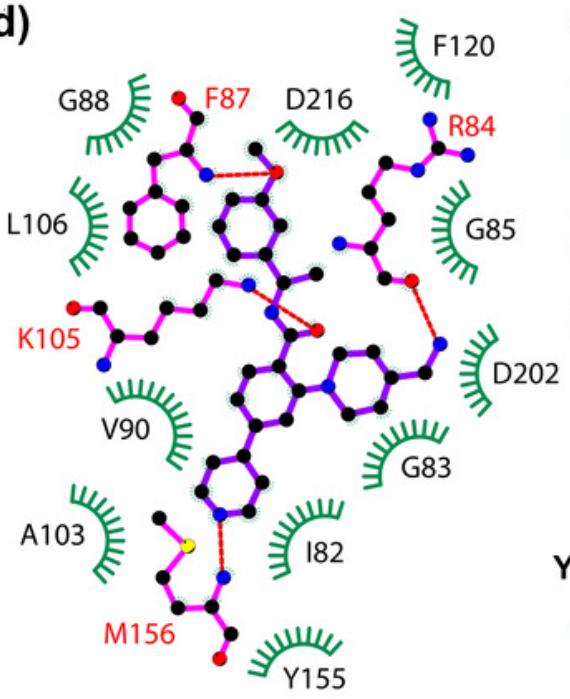

b)

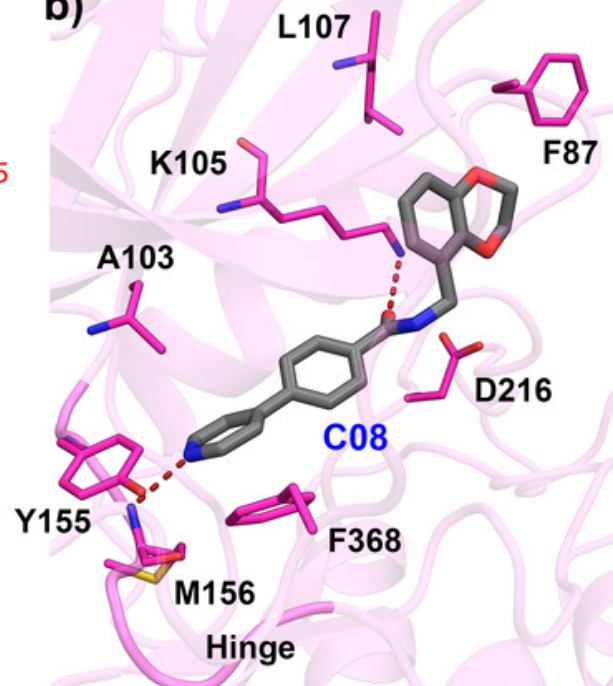

e)

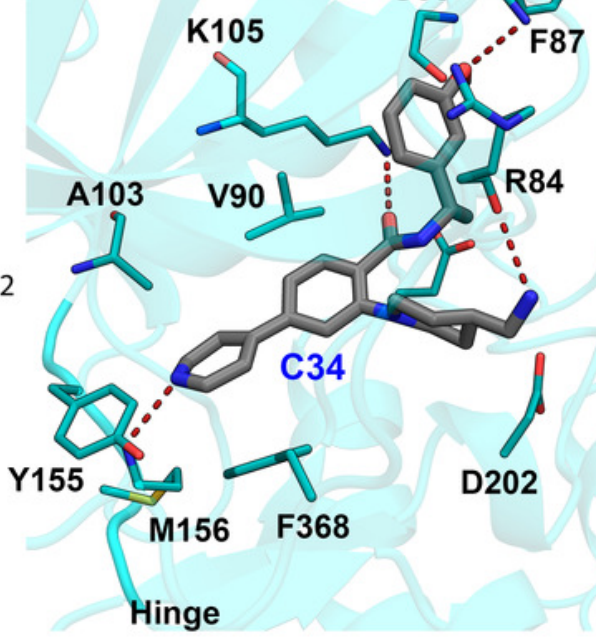

c)
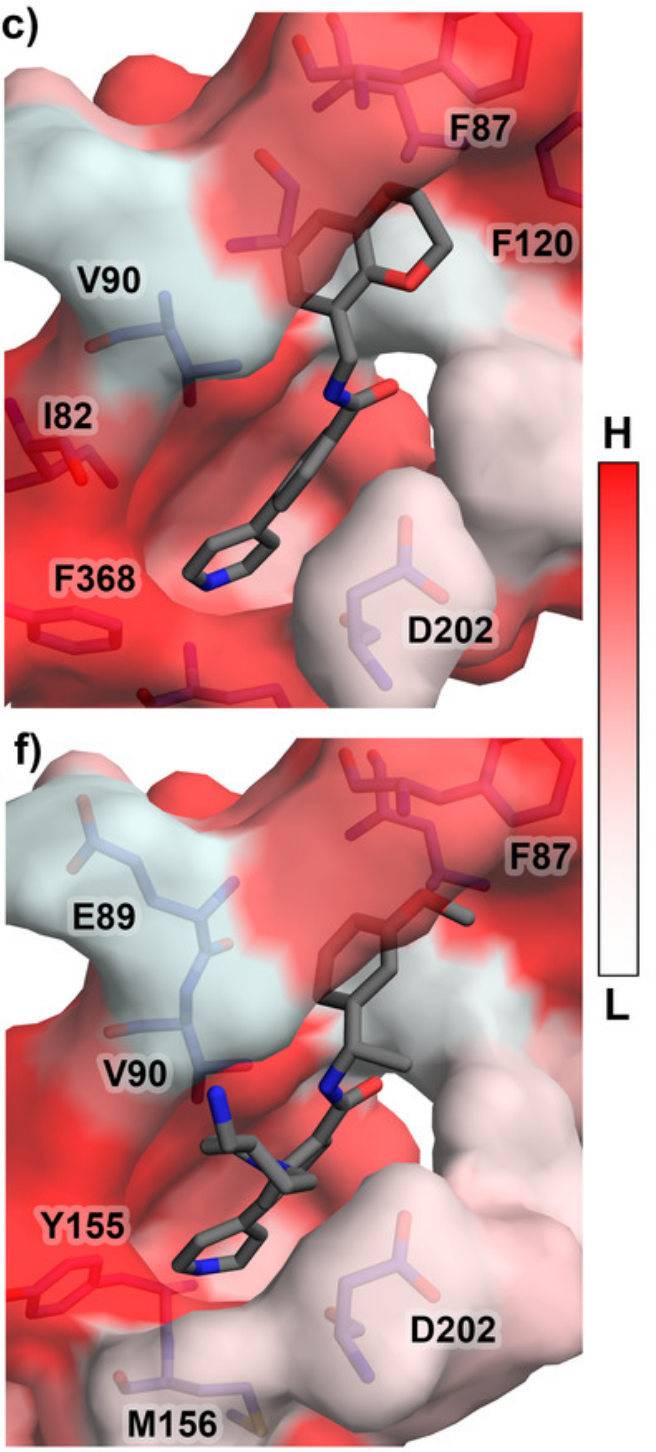
Figure 3

Average MD pose of the ligands inside the ROCK1 active site

Final 1 ns average MD pose of the compound a) $\mathrm{C} 03$, b) $\mathrm{C} 08$, c) $\mathrm{C} 11$, d) $\mathrm{C} 13$, e) $\mathrm{C} 19$, f) $\mathrm{C} 22$,

g) $\mathrm{C} 25$, h) $\mathrm{C} 29$, i) $\mathrm{C} 34$, and j) $\mathrm{C} 37$ in dark-grey respectively inside the ROCK1 binding pocket.

The corresponding docked pose of each compound was shown in salmon color. The $\mathrm{H}$-bond interactions have been marked by red dashed lines. 

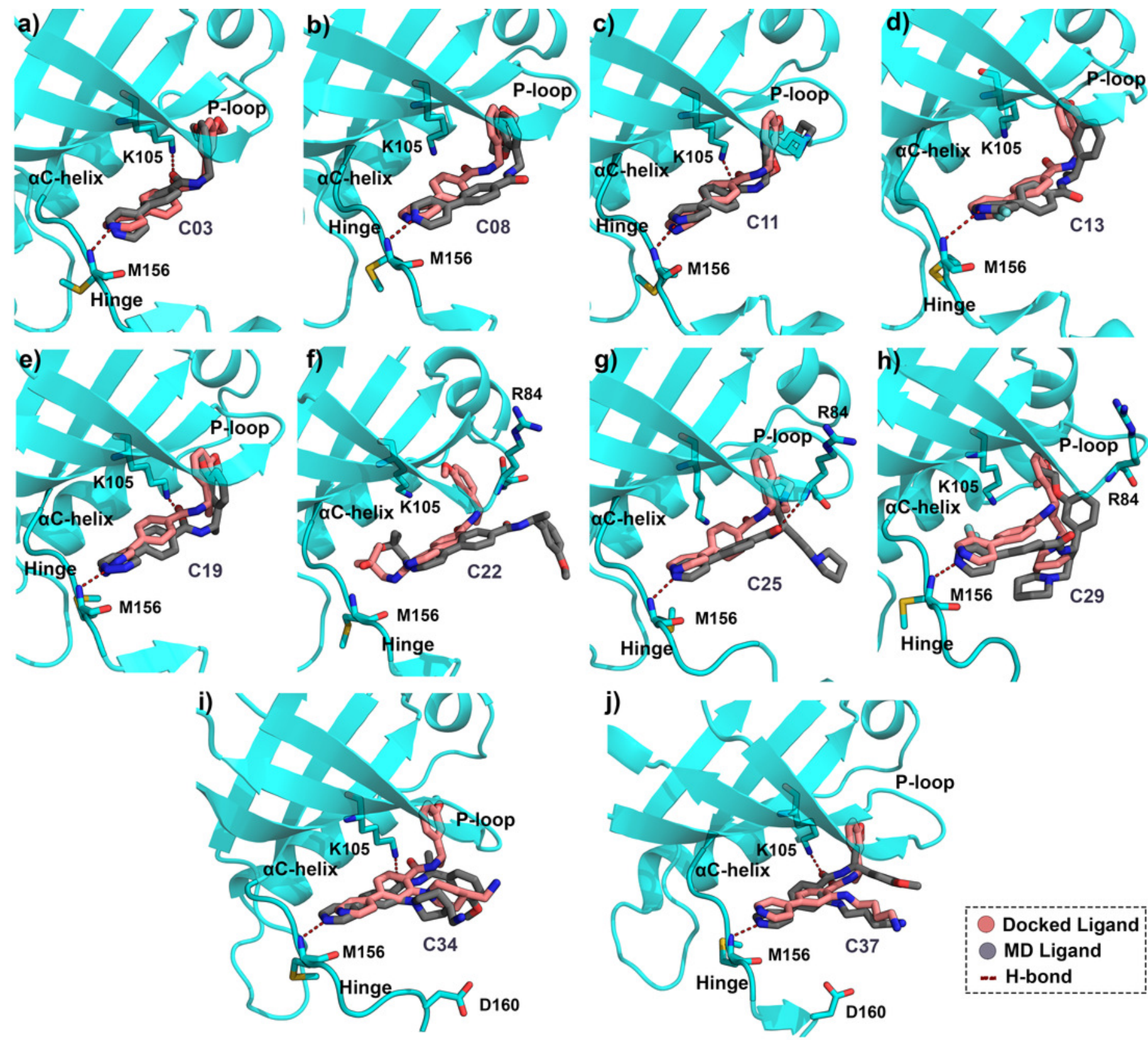
Figure 4

$\mathrm{H}$-bond interaction distance between the M256 and selected compounds during the MD run

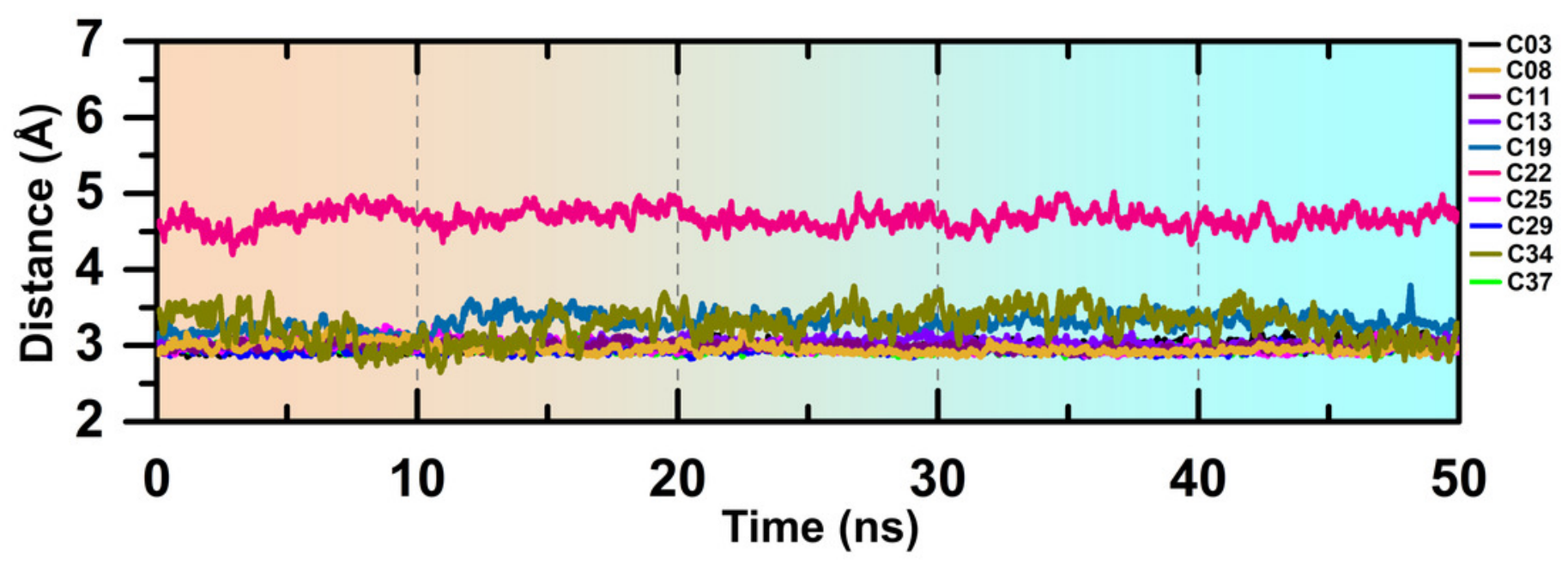


Figure 5

Residue-wise MMPBSA binding energy decomposition in $\mathrm{kJ} / \mathrm{mol}$

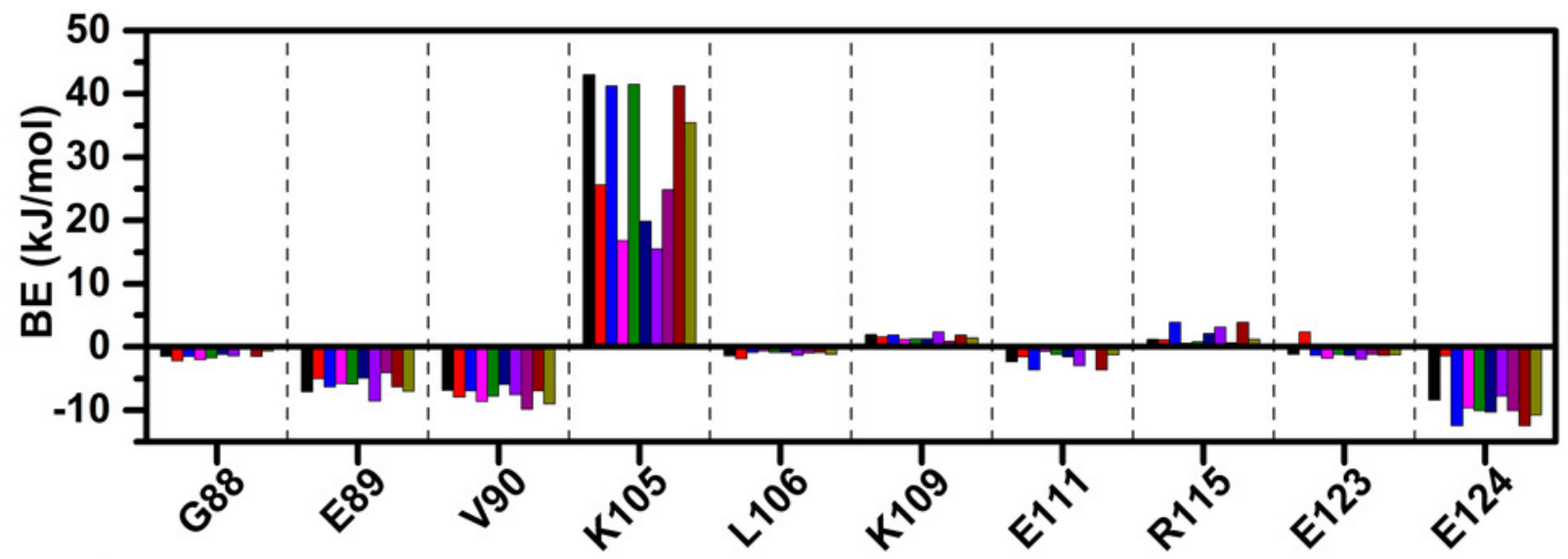

ROCK1-C03

ROCK1-C08

ROCK1-C11

ROCK1-C13

ROCK1-C19

ROCK1-C22

ROCK1-C25

ROCK1-C29

ROCK1-C34
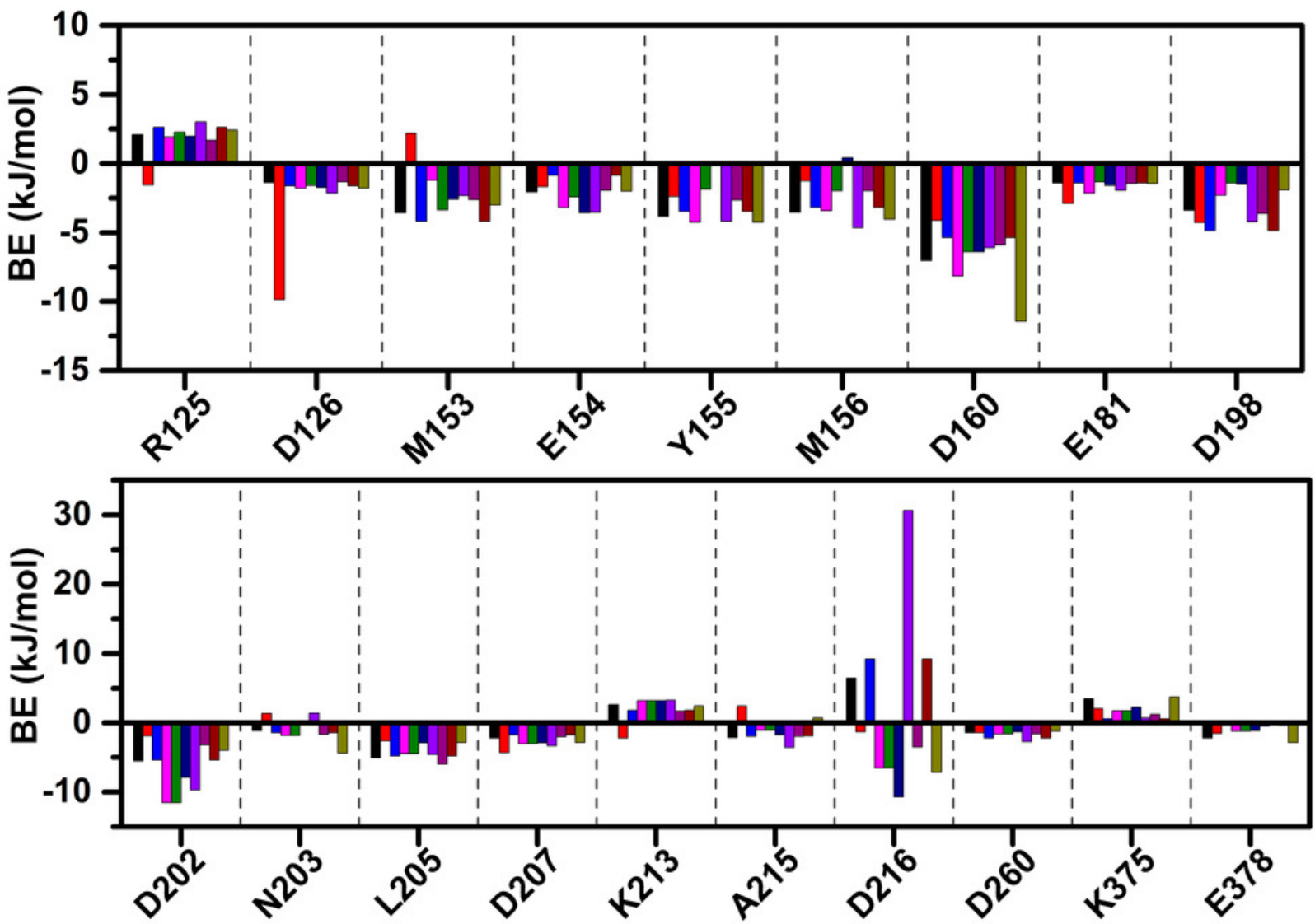


\section{Figure 6}

PLS regression plot and Contour map assessment from CoMFA and CoMSIA around the $\mathrm{C} 08$

a) PLS statistical plot from CoMFA, where training sets and test sets are shown by forestgreen and light-green color. b) and c) are the contour maps, displaying the favorable substitution for the steric and electrostatic chemical groups. Green contour represents the favorable regions for a bulky group, and yellow contour represents the unfavorable regions of that substitution. Blue contour favored the positively charged chemical group, and red contour unfavored that substitution in CoMFA analysis. d) PLS statistical plot from CoMSIA, where training sets and test sets are shown by forest-green and light-green color. e) and f) are the contour maps, displaying the favorable substitution for the steric and electrostatic substitution. Green contour signifies the favorable regions for a bulky group, and yellow contour signifies the sterically unfavorable regions for that substitution. Blue contour favored the positively charged electrostatic substitution, whereas, red contour unfavored that substitution in CoMSIA analysis. 

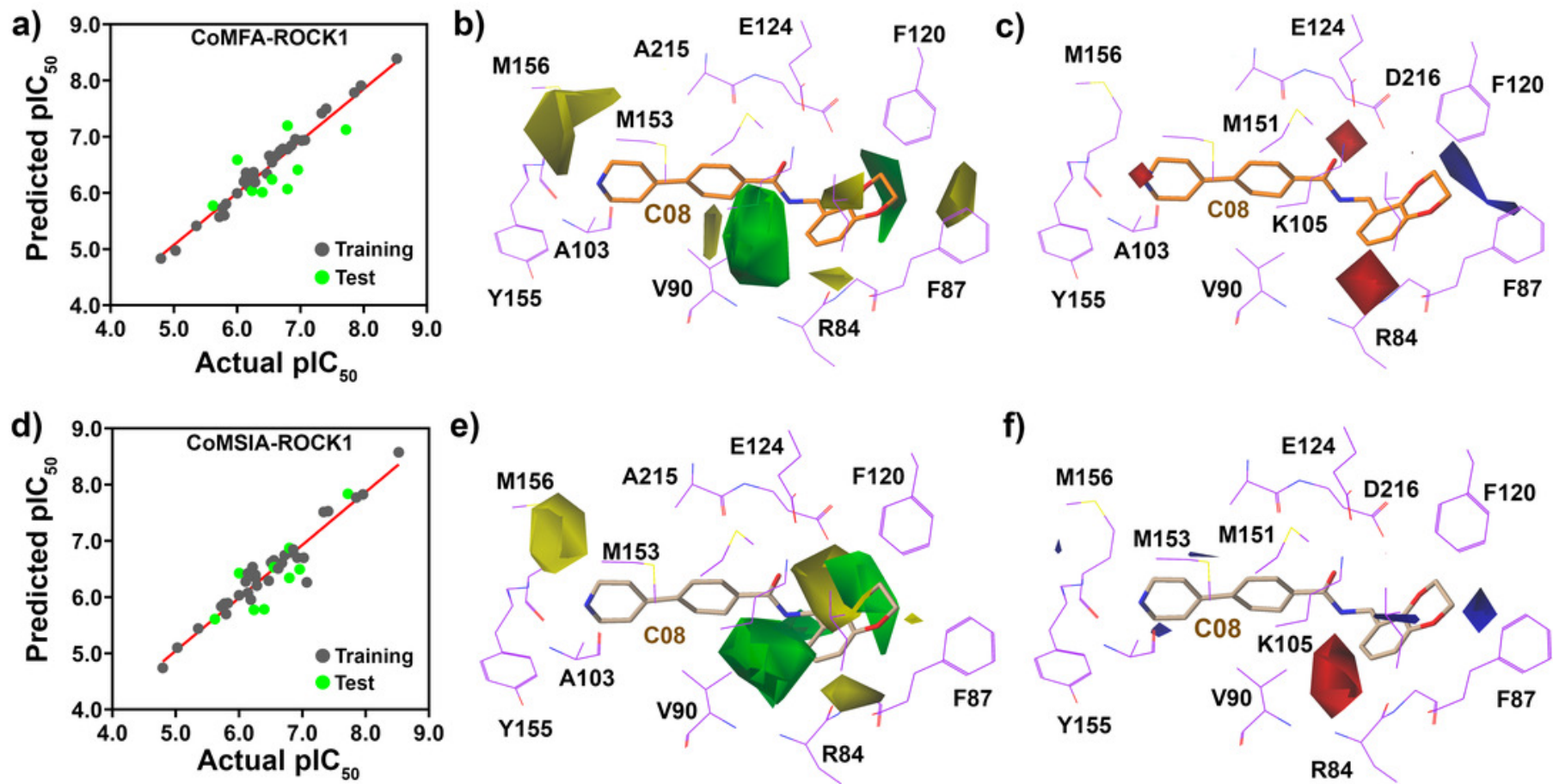
Figure 7

Diagram of the three-dimensional structure-activity relationship of the representative compound C08

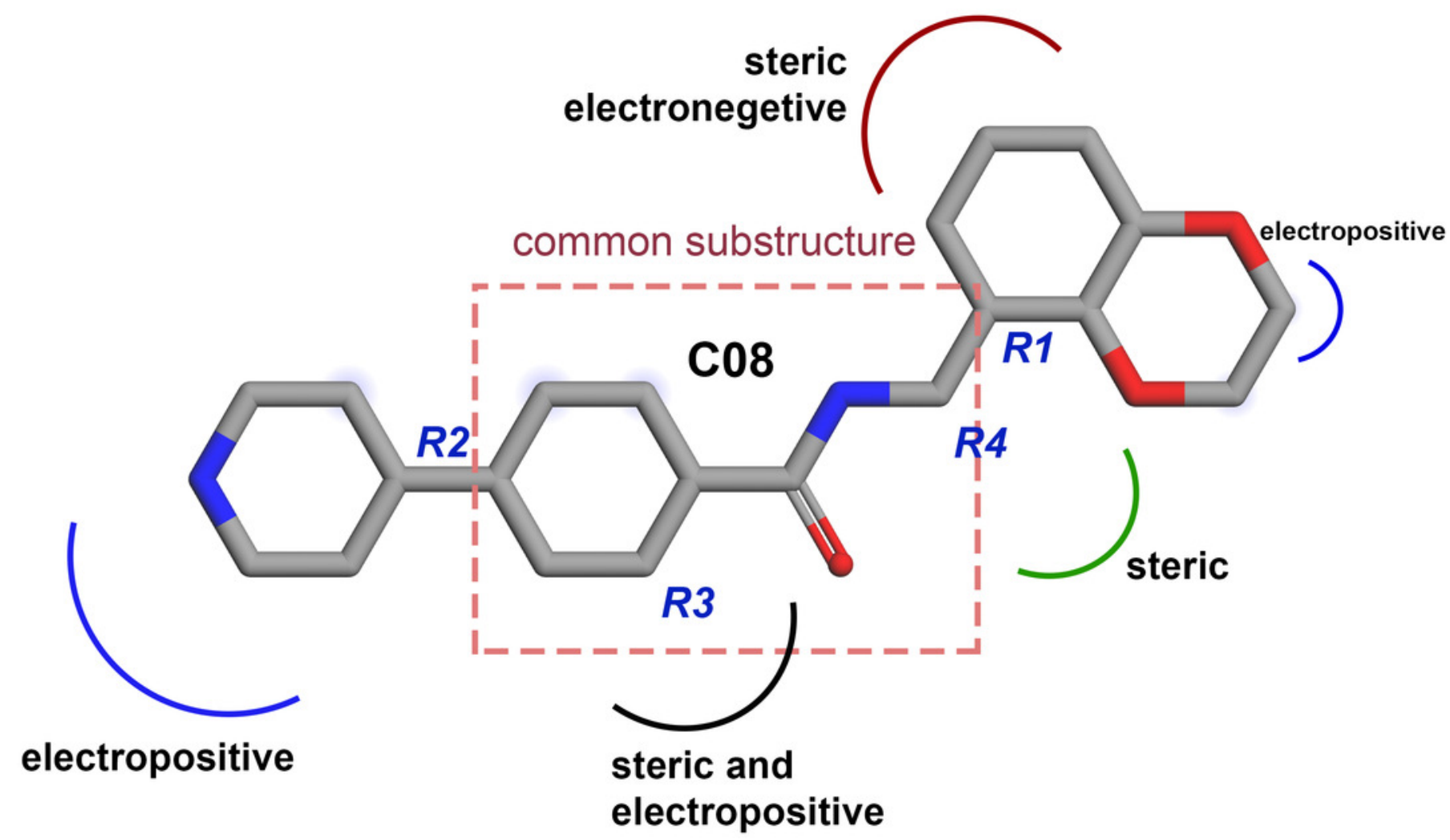


Figure 8

Average MD pose of the designed compound in the ATP pocket

Final 1 ns average MD pose of the designed compound a) D02, b) D03, c) D06, d) D31, e) D32, f) D33, and g) D35 respectively. The H-bond interaction was shown by red dashed lines.
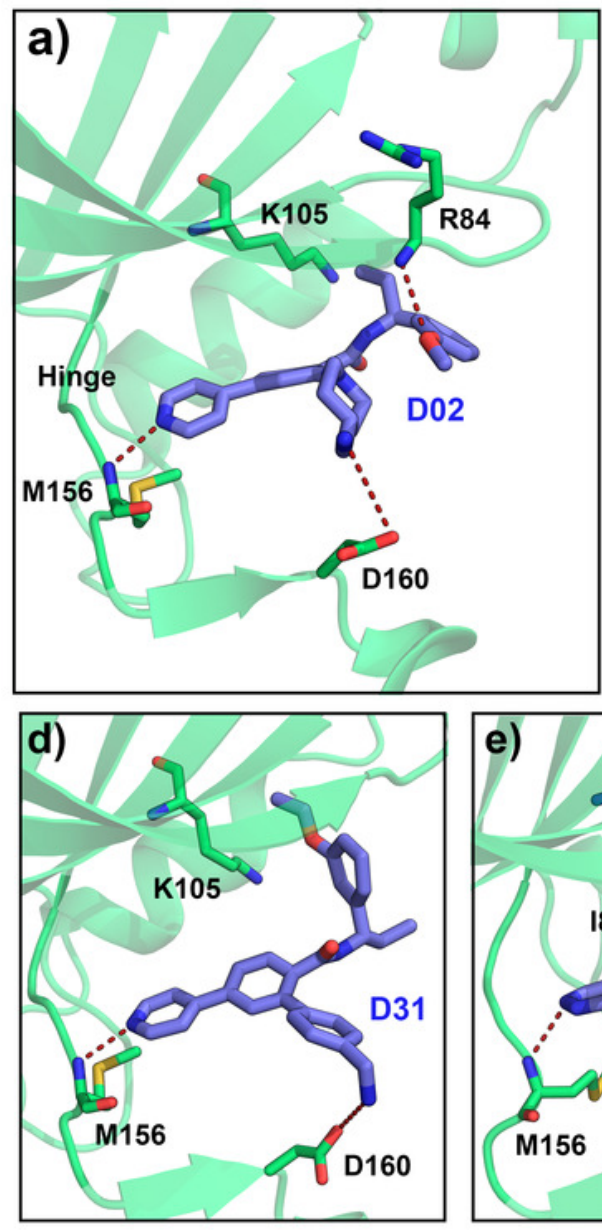
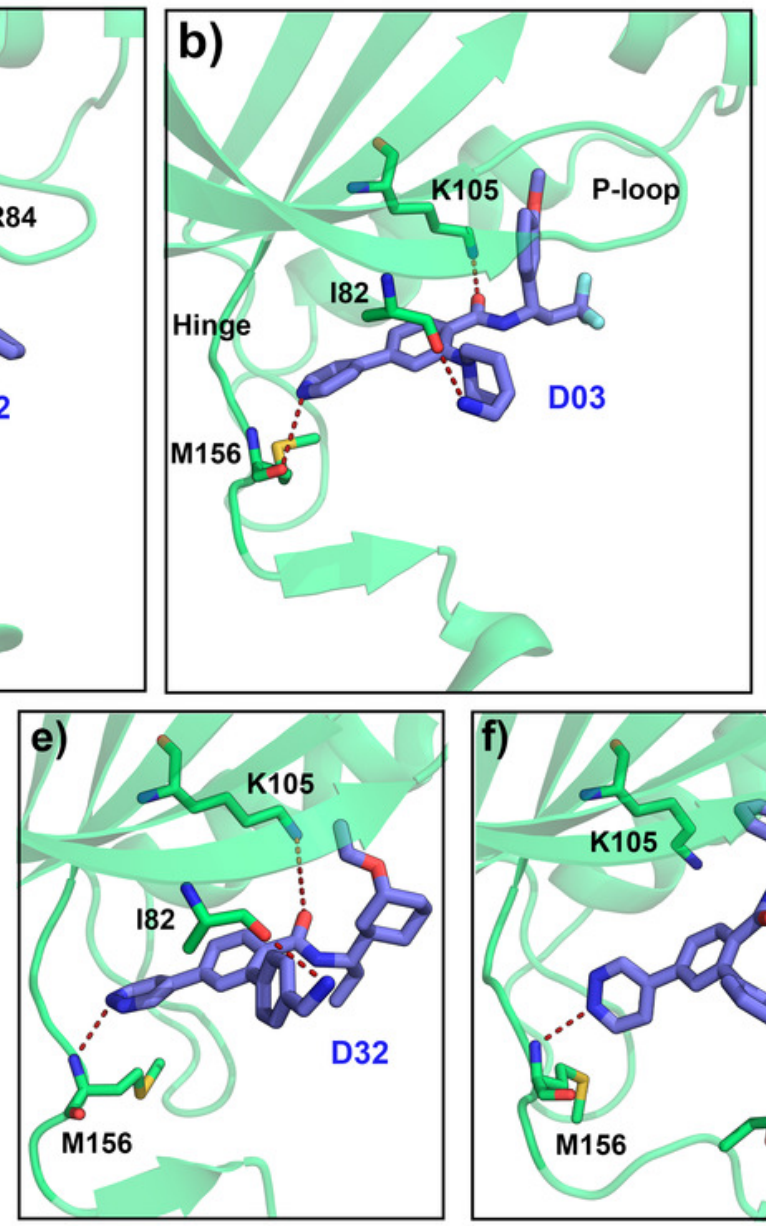
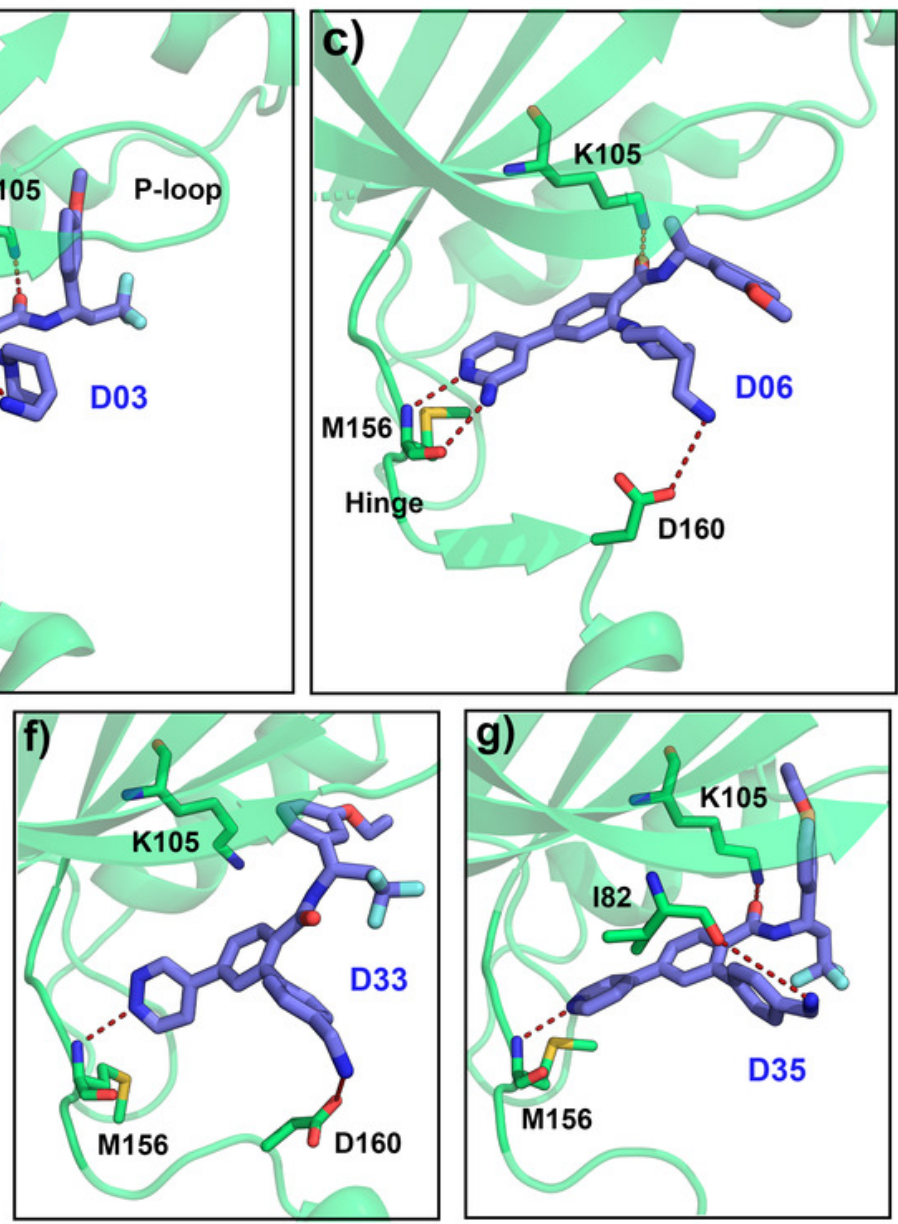
Figure 9

Comparison of the residue-wise MMPBSA binding energy contribution to the newly designed compounds

For the assessment, the residues were selected within the $3.5 \AA$ distance from the ligand. Residues with net positive BE decomposition are shown in hot-pink color, residues with net negative BE decomposition are shown in the slate color. The active site was represented by a grey surface scheme.
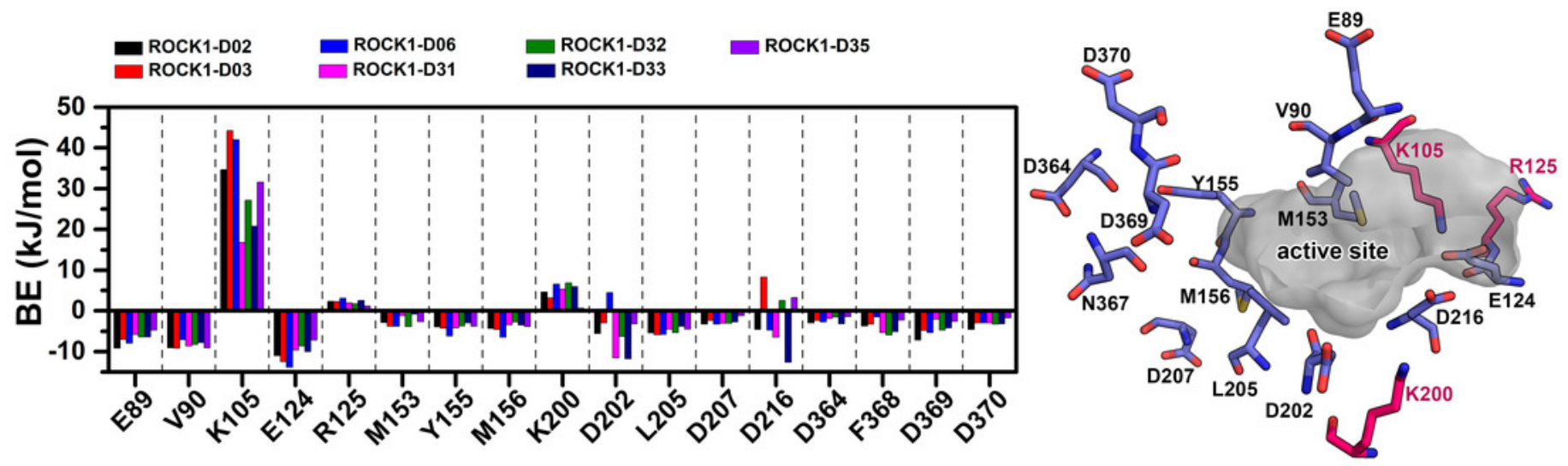
Table $\mathbf{1}$ (on next page)

MMPBSA and IE estimation of the compound C03, C08, C11, C13, C19, C22, C25, C29, C34 and C37 


\begin{tabular}{|c|c|c|c|c|c|c|}
\hline \multirow[t]{2}{*}{ \#Cpd. } & \multicolumn{5}{|c|}{ MMPBSA binding energy terms in $\mathrm{kJ} / \mathrm{mol}$} & \multirow{2}{*}{$\begin{array}{c}\text { Interaction } \\
\text { Energy (IE) } \\
\text { in } \mathrm{kJ} / \mathrm{mol} \\
( \pm \mathrm{SE})\end{array}$} \\
\hline & $\begin{array}{l}\text { van der } \\
\text { Waals } \\
\text { energy } \\
( \pm S D)\end{array}$ & $\begin{array}{c}\text { Electrostatic } \\
\text { energy } \\
( \pm S D)\end{array}$ & $\begin{array}{c}\text { Polar } \\
\text { solvation } \\
\text { energy } \\
( \pm S D)\end{array}$ & $\begin{array}{l}\text { SASA } \\
\text { energy } \\
( \pm S D)\end{array}$ & $\begin{array}{l}\text { Total } \\
\text { Binding } \\
\text { energy } \\
( \pm S D)\end{array}$ & \\
\hline $\mathrm{CO3}$ & $-172.3 \pm 4.2$ & $-74.6 \pm 5.0$ & $158.1 \pm 2.0$ & $-19.2 \pm 0.2$ & $\mathbf{- 1 0 7 . 8} \pm 2.9$ & $\mathbf{- 2 5 3 . 4 1} \pm 1.7$ \\
\hline $\mathrm{C08}$ & $-164.2 \pm 10.3$ & $-31.2 \pm 4.5$ & $103.7 \pm 6.4$ & $-17.7 \pm 0.3$ & $\mathbf{- 1 0 9 . 2} \pm 4.6$ & $\mathbf{- 2 4 7 . 9 7} \pm 2.5$ \\
\hline C11 & $-194.7 \pm 5.2$ & $-81.4 \pm 1.7$ & $186.7 \pm 10.8$ & $-23.1 \pm 0.3$ & $\mathbf{- 1 1 4 . 0} \pm 9.6$ & $\mathbf{- 2 7 9 . 6 9} \pm 3.6$ \\
\hline C13 & $-157.0 \pm 3.9$ & $-28.7 \pm 3.3$ & $102.5 \pm 4.5$ & $-19.0 \pm 0.2$ & $\mathbf{- 1 0 2 . 3} \pm 1.8$ & $\mathbf{- 1 9 4 . 2 6} \pm 2.9$ \\
\hline C19 & $-158.8 \pm 0.4$ & $-68.2 \pm 0.4$ & $169.1 \pm 0.6$ & $-18.1 \pm 0.1$ & $\mathbf{- 7 6 . 0} \pm 0.7$ & $\mathbf{- 2 1 5 . 3 7} \pm 5.2$ \\
\hline $\mathrm{C} 22$ & $-138.2 \pm 0.6$ & $-36.9 \pm 0.6$ & $96.9 \pm 1.0$ & $-17.2 \pm 0.1$ & $\mathbf{- 9 5 . 4} \pm 0.8$ & $\mathbf{- 2 1 0 . 9 3} \pm 1.7$ \\
\hline C25 & $-189.8 \pm 4.7$ & $-50.2 \pm 1.2$ & $138.4 \pm 4.8$ & $-21.5 \pm 0.9$ & $\mathbf{- 1 2 3 . 1} \pm 0.3$ & $\mathbf{- 2 8 4 . 7 5} \pm 2.2$ \\
\hline $\mathrm{C} 29$ & $-165.5 \pm 2.1$ & $-49.2 \pm 1.2$ & $125.3 \pm 4.9$ & $-19.6 \pm 0.1$ & $\mathbf{- 1 0 8 . 8} \pm 7.8$ & $\mathbf{- 2 2 6 . 2 1} \pm 4.1$ \\
\hline C34 & $-203.3 \pm 0.6$ & $-76.6 \pm 0.4$ & $172.9 \pm 0.7$ & $-23.5 \pm 0.1$ & $\mathbf{- 1 3 0 . 6} \pm 0.7$ & $\mathbf{- 2 8 4 . 2 1} \pm 4.8$ \\
\hline C37 & $-186.8 \pm 1.0$ & $-48.9 \pm 1.4$ & $148.8 \pm 8.6$ & $-19.8 \pm 0.2$ & $\mathbf{- 1 0 6 . 6} \pm 6.9$ & $\mathbf{- 2 3 3 . 9 3} \pm 3.7$ \\
\hline
\end{tabular}

1 \#Cpd.: Compounds; SD: Standard Deviation; SE: Standard Error 
Table 2 (on next page)

Structure and activity values of N-ethyl-4-(pyridin-4-yl)benzamide based ROCK1 inhibitor 
1<smiles>[R]c1ccc(C(=O)NC([R])[R])c([R3])c1</smiles><smiles>CC(C)c1ccncc1</smiles><smiles>COc1cccc(C(C)C)c1</smiles>

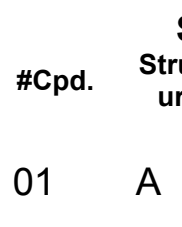

Structure A Struct R1

Structure B

02 A C

03<smiles>CCOc1cccc(C(C)C)c1</smiles>

04
A<smiles>CCCOc1cccc(C(C)C)c1</smiles>

\#05 A<smiles>CC(C)c1cccc(O)c1</smiles>

06<smiles>CC(C)c1ccccc1</smiles>

B

B

B

B

B

B

07 A<smiles>CC(C)c1cccc(CC(F)(F)F)c1</smiles>

B<smiles>COc1cccc(C(C)C)c1OC</smiles>

08

A<smiles>CC(C)c1cccc2c1OCCO2</smiles>

\#09

A<smiles>CC(C)c1cccc2c1OCCCO2</smiles>

B<smiles>[B]N(C)CCCOc1cccc(C(C)(C)C)c1</smiles>

11
A<smiles>CC(C)c1cccc(OCCN2CCOCC2)c1</smiles>

R2

\section{Structure C}

R3

$\xi \mathrm{H}$

$\xi \mathrm{H}$

$\xi \mathrm{H}$

$\xi \mathrm{H}$

$\xi \mathrm{H}$

$\xi \mathrm{H}$

$\xi \mathrm{H}$

$\xi \mathrm{H}$

$\xi \mathrm{H}$

$\xi \mathrm{H}$

$\xi \mathrm{H}$

$\xi \mathrm{H}$

$\xi \mathrm{H}$

$\xi \mathrm{H}$

$\xi \mathrm{H}$

$\xi \mathrm{H}$

$\xi \mathrm{H}$

$\xi \mathrm{H}$

$\xi \mathrm{H}$

$\xi \mathrm{H}$
$\mathrm{CH}_{3}$

Structure D

R4

$\mathrm{plC}_{50}$
(ROCK1)

6.25

6.79

6.10

6.28

7.72

5.35

7.79

6.55

6.55

6.46

B $\xi \mathrm{H}$

$\xi \mathrm{H}$

6.00 
12 A C<smiles>CC(C)c1ccnc(N)c1</smiles>

D

\#13 A C<smiles>CC(C)c1ccnc(F)c1</smiles>

$\xi \mathrm{H}$

D

7.07

14 A C<smiles>CCc1ccnc(Cl)c1</smiles>

$\xi \mathrm{H}$

6.14

15 A C<smiles>Cc1cc(C(C)C)ccn1</smiles>

$\xi \mathrm{H}$

D

6.21<smiles>Cc1cc(C(C)C)cc(C)n1</smiles>

$\xi \mathrm{H}$

D

NA

16 A C<smiles>CC(C)c1ccncc1F</smiles>

$\xi \mathrm{H}$

D<smiles>CC(C)c1ccncn1</smiles>

$\xi \mathrm{H}$

D

6.67

19 A C<smiles>CC(C)c1ccnnc1</smiles>

$\xi \mathrm{H}$

20 A C<smiles>CCNc1cc(C(C)(C)C)ccn1</smiles>

D<smiles>CC(C)c1ccnc(NCC2CC2)c1</smiles>

D

${ }^{\# 21} \mathrm{~A} \quad \mathrm{C}$<smiles>CC(C)c1ccnc(NCC(C)(C)O)c1</smiles>

D

5.61

23 A $\quad$ C<smiles>COCCNc1cc(C(C)(C)C)ccn1</smiles>

D

\#24 A C<smiles>COCCCNc1cc(C(C)(C)C)ccn1</smiles>

D

25

A<smiles>CC(C)c1ccccc1</smiles><smiles>CC(C)c1ccncc1</smiles>

$\xi \mathrm{H}$<smiles>CC(C)CCN1CCCC1</smiles> 
26 A C

$27 \quad A \quad$ C

\#28 A C

29 A<smiles>CCCOc1cccc(C(C)C)c1</smiles>

30<smiles>CC(C)c1cccc(F)c1</smiles>

31
A<smiles>CCCOc1cccc(C(C)(C)C)c1</smiles>

32
A<smiles>CCCOc1cccc(C(C)(C)C)c1</smiles>

33
A<smiles>CCCOc1cccc(C(C)C)c1</smiles>

34 A C

\#35 A C

36 A C

$37 \quad A \quad C$

\#38 A C

39

A<smiles>CCCOc1cccc(C(C)C)c1</smiles>

40<smiles>CC(C)c1ccncc1</smiles><smiles>CC(C)c1ccncc1</smiles><smiles>CC(C)c1ccnc(F)c1</smiles><smiles>CC(C)c1ccnc(F)c1</smiles><smiles>CC(C)c1ccnc(F)c1</smiles><smiles>CC(C)c1ccnc(F)c1</smiles><smiles>CC(C)c1ccncc1F</smiles><smiles>CC(C)c1ccncc1</smiles>

B

B

B

B<smiles>CC(C)c1ccncn1</smiles><smiles>CCCOc1cccc(C(C)C)c1</smiles>

$\xi \mathrm{H}$

$\xi \mathrm{H}$<smiles>CC(C)CCN1CCCC1</smiles>

7.85

$\xi \mathrm{H}$

$\xi \mathrm{H}$<smiles>CC(C)CCO</smiles><smiles>CC(C)CCN1CCOCC1</smiles><smiles>CC(C)CCN1CCCCC1</smiles>

6.25

$\xi \mathrm{H}$<smiles>CC(C)CCN1CCCC1</smiles>

6.61

$\xi \mathrm{H}$<smiles>CC(C)CCO</smiles>

$\xi \mathrm{H}$<smiles>CCCC(C)CO</smiles>

$\xi \mathrm{H}$

D

6.79

$\mathrm{N}^{\mathrm{NH}} \mathrm{N}$<smiles>CC(C)c1ccncn1</smiles>

$\stackrel{\mathrm{N}}{\sim} \sim \mathrm{NH}_{2} \quad \mathrm{D}$

$\stackrel{\mathrm{H}}{\sim} \sim \mathrm{NH}_{2} \quad \mathrm{D}$

$\stackrel{\mathrm{H}}{\sim} \mathrm{NH}_{\mathrm{D}}$

6.50

$\mathrm{N}_{\mathrm{H}} \sim \mathrm{NH}_{2}$

6.01

$\prod_{\ldots+1}^{\mathrm{NH}_{2}} \mathrm{D}$

5.72

$\longrightarrow \mathrm{NH}^{\mathrm{NH}_{2}} \mathrm{D}$

8.52

6.72

7.03<smiles>CCc1ccncn1</smiles> 
41 A $\quad$ C

$42 \quad \mathrm{~A} \quad \mathrm{C}$

\#) Test Set compound. Cpd.: Compounds

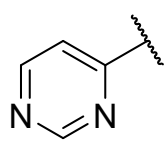

$\sim \mathrm{NH}_{2} \quad \mathrm{D}$

6.79

${ }^{\mathrm{N}} \widehat{\mathrm{NH}}^{\mathrm{D}} \mathrm{D}$ 
Table 3 (on next page)

Statistics of the selected CoMFA and CoMSIA models 
1

\begin{tabular}{ccc}
\hline Parameters & CoMFA & CoMSIA (SE) \\
\hline $\boldsymbol{q}^{\mathbf{2}}$ & 0.774 & 0.676 \\
\hline ONC & 6 & 6 \\
\hline SEP & 0.425 & 0.509 \\
\hline $\boldsymbol{r}^{\mathbf{2}}$ & 0.965 & 0.949 \\
\hline SEE & 0.167 & 0.201 \\
\hline F-value & 114.795 & 78.237 \\
\hline $\boldsymbol{r}^{2}$ pred & 0.703 & 0.548 \\
\hline S (\%) & 63.0 & 57.2 \\
\hline E (\%) & 37.0 & 42.8 \\
\hline
\end{tabular}

$2 \quad q^{2}$ : squared cross-validated correlation coefficient; ONC: optimal number of components; SEP:

3 standard error of prediction; $\boldsymbol{r}^{2}$ : squared correlation coefficient; SEE: standard error of estimation;

4 F-value: F-test value; $\boldsymbol{r}_{\text {pred }}$ : predictive $\boldsymbol{r}^{2}$; $\mathbf{S}$ : steric; E: electrostatic.

5 


\section{Table 4 (on next page)}

Newly designed compounds with higher predicted $\mathrm{plC}_{50}$ values 
<smiles>[R]c1ccc(C(=O)NC([R])[R])c([R2])c1</smiles>

Structure A

\begin{tabular}{|c|c|c|c|c|c|c|}
\hline \\
\hline \#Cpd. & Structure & $\mathbf{R}_{1}$ & $\mathbf{R}_{\mathbf{2}}$ & $\mathbf{R}_{\mathbf{3}}$ & $\mathbf{R}_{\mathbf{4}}$ & $\begin{array}{l}\mathbf{p l C}_{50} \\
(\text { CoMFA) }\end{array}$ \\
\hline D02 & A & & & & & 8.77 \\
\hline D03 & A & & & & & 8.59 \\
\hline D06 & A & & & & & 8.58 \\
\hline D31 & $A$ & & & & & 8.78 \\
\hline D32 & A & & & & & 8.61 \\
\hline D33 & $A$ & IV & & & & 8.58 \\
\hline D35 & A & & & & & 8.74 \\
\hline
\end{tabular}

\#Cpd.: Compounds. 
Table 5 (on next page)

MMPBSA and IE estimation of the compound D02, D03, D06, D31, D32, D33, and D35 


\begin{tabular}{|c|c|c|c|c|c|c|}
\hline \multirow[t]{2}{*}{ \#Cpd. } & \multicolumn{5}{|c|}{ MMPBSA binding energy terms in $\mathrm{kJ} / \mathrm{mol}$} & \multirow{2}{*}{$\begin{array}{c}\text { Interaction } \\
\text { Energy (IE) in } \\
\text { kJ/mol } \\
( \pm S E)\end{array}$} \\
\hline & $\begin{array}{c}\text { van der Waals } \\
\text { energy } \\
( \pm S D)\end{array}$ & $\begin{array}{c}\text { Electrostatic } \\
\text { energy } \\
( \pm S D)\end{array}$ & $\begin{array}{c}\text { Polar } \\
\text { solvation } \\
\text { energy } \\
( \pm S D)\end{array}$ & $\begin{array}{c}\text { SASA } \\
\text { energy } \\
( \pm S D)\end{array}$ & $\begin{array}{c}\text { Total Binding } \\
\text { energy } \\
( \pm S D)\end{array}$ & \\
\hline D02 & $-203.8 \pm 6.1$ & $-37.7 \pm 3.3$ & $126.6 \pm 4.3$ & $-22.2 \pm 0.5$ & $\mathbf{- 1 3 7 . 0} \pm 2.6$ & $\mathbf{- 2 4 5 . 0} \pm 3.4$ \\
\hline D03 & $-224.5 \pm 2.5$ & $-72.1 \pm 1.6$ & $187.0 \pm 4.7$ & $-24.9 \pm 0.4$ & $\mathbf{- 1 3 4 . 7} \pm 8.1$ & $-\mathbf{2 8 0 . 1} \pm 2.7$ \\
\hline D06 & $-191.7 \pm 4.4$ & $-97.9 \pm 2.4$ & $202.8 \pm 4.9$ & $-22.7 \pm 0.3$ & $\mathbf{- 1 0 9 . 6} \pm 5.6$ & $\mathbf{- 2 2 3 . 4} \pm 5.9$ \\
\hline D31 & $-169.1 \pm 0.5$ & $-28.5 \pm 0.4$ & $78.7 \pm 0.8$ & $-20.2 \pm 0.1$ & $\mathbf{- 1 3 9 . 2} \pm 0.7$ & $\mathbf{- 2 0 4 . 9} \pm 3.9$ \\
\hline D32 & $-192.8 \pm 4.8$ & $-68.9 \pm 2.0$ & $169.6 \pm 12.1$ & $-23.0 \pm 0.5$ & $\mathbf{- 1 1 5 . 3} \pm 5.6$ & $\mathbf{- 2 2 7 . 4} \pm 1.4$ \\
\hline D33 & $-191.4 \pm 2.4$ & $-31.4 \pm 1.3$ & $104.0 \pm 1.2$ & $-21.3 \pm 0.1$ & $\mathbf{- 1 4 0 . 1} \pm 0.2$ & $-214.9 \pm 2.4$ \\
\hline D35 & $-189.5 \pm 2.0$ & $-57.2 \pm 3.4$ & $134.2 \pm 4.3$ & $-22.7 \pm 0.2$ & $-\mathbf{1 3 5 . 0} \pm 5.8$ & $\mathbf{- 2 4 8 . 0} \pm 1.1$ \\
\hline
\end{tabular}

1 \#Cpd.: Compounds; SD: Standard Deviation; SE: Standard Error

2

3 